\title{
PETROGRAFÍA DE LA CERÁMICA NIMUN Y BACA (VAJILLA CELESTÚN ROJA): ESFERA CERÁMICA CANBALAM DE LA PENÍNSULA DE YUCATÁN, MÉXICO
}

\author{
PETROGRAPHY OF THE NIMUN AND BACA POTTERY (WARE CELESTÚN \\ ROJA): CANBALAM CERAMIC SPHERE OF THE YUCATAN PENINSULA, \\ MEXICO
}

\author{
Luis G. Obando ${ }^{1 *} \&$ Socorro del P. Jiménez ${ }^{2}$ \\ ${ }^{1}$ Escuela Centroamericana de Geología, Universidad de Costa Rica, \\ Apdo. 214-2060 UCR \\ ${ }^{2}$ Socorro del Pilar Jiménez Álvarez, Facultad de Ciencias Antropológicas, \\ Universidad Autónoma de Yucatán, Mérida, Yucatán, México \\ *Autor para contacto: luis.obando@ucr.ac.cr.
}

(Recibido: 12/01/2015; aceptado: 23/01/2016)

\begin{abstract}
The ware Celestún Red (of the Nimun and Baca ceramic typologies) is one of the most diagnostic ceramics of the northwestern coast of Mexico's Yucatan Peninsula and a subject of ongoing debate regarding its distribution and origin. Although ceramics from coastal Campeche and Yucatan have been the focus of years of investigation, scholars still do not know if Celestún Red was manufactured locally during the Late Classic (A.D. 600-900) or was made and exchanged by the regional elite. In this presentation, the authors provide the first petrographic descriptions of Celestún Red, and use them to contribute to a formal definition of the Cambalan Ceramic Sphere defined by Jiménez (2002), Jiménez, Ceballos \& Sierra (2006). These petrographic observations show that the detrital components were rhyolite fragments, vitroclastic tuffs, pumice, shards of glass, quartzes, plagioclase, calcite, hematite, magnetite and other minor contributors. The clay matrix is phyllomorphic, with a parallel, rectilinear fabric of fine grains. Granulometrically, the detrital components have been characterized as fine to medium sands. The pastes present evidence of diagenetic processes, most notably porosity in the primary ceramic matrix. These spaces are in some cases filled by secondary calcite deposits. Evidence of manufacturing was also observed, such as the fractures and bending of the paste that took place to produce the rims of these ceramic objects.

Keywords: Geoarchaeology, ceramic analysis, ware Celestún Red, Cambalan Ceramic Sphere, Late Classic.
\end{abstract}

RESUMEN: La Vajilla Celestún Roja (tipos cerámicos Nimun y Baca) es una de las cerámicas más representativas de la costa noroeste de la Península de Yucatán, en México, cuya distribución y origen representan un fuerte tema de debate. Aunque la cerámica de las costas de Campeche y Yucatán por años ha sido objeto de investigación, los expertos en

OBANDO, L. G. \& JIMÉNEZ, S. P., 2016: Petrografía de la cerámica Nimun y Baca (Vajilla Celestún Roja): Esfera Cerámica Canbalam de la península de Yucatán, México.- Rev. Geol. Amér. Central, 54: 85-108, DOI: 10.15517/rgac.v54i0.21150 
el tema aún no logran descifrar si la Vajilla Celestún Roja fue fabricada localmente durante el Clásico Tardío (600-900 d.C.), o si los objetos cerámicos que se han hallado fueron elaborados e intercambiados por la élite regional. Se describe por primera vez la petrografía de la Vajilla Celestún Roja de la tipología Nimun y Baca, como aporte a la definición formal de la llamada Esfera Cerámica Cambalan definida por Jiménez (2002), Jiménez, Ceballos \& Sierra (2006). Las observaciones petrográficas muestran que los componentes detríticos son fragmentos riolíticos, tobas vitroclásticas, pómez, esquirlas de vidrio, cuarzos, plagioclasas, calcita, hematita, magnetita y otros menores. La matriz arcillosa es filomórfica con fábricas paralelas, reticuladas y granulares finas. Los componentes detríticos son granulométricamente arenas finas a medias. Las pastas presentan procesos diagenéticos que han afectado la porosidad primaria y muestran relleno de poros y reemplazo mineral por calcitas secundarias. Se han observado evidencias de los procesos de manufactura como fracturas y doblamiento de pastas al confeccionar los bordes de los objetos cerámicos.

Palabras clave: Geoarqueología, análisis cerámico, vajilla Celestún Roja, Esfera Cerámica Cambalan, Clásico Tardío.

\section{INTRODUCCIÓN}

La cerámica del período Clásico Tardío de la franja costera peninsular de Campeche y Yucatán, México ha sido integrada a la llamada Esfera Cerámica Canbalam, la cual, como un constructo analítico en los estudios cerámicos del área Maya, le ha servido a los arqueólogos investigadores para enfatizar el alto grado de similitud existente entre el material cerámico (tipos cerámicos) localizados en este extenso territorio (Jiménez, 2002, 2009; Jiménez et al., 2006a). La pasta de la Vajilla Celestún Roja, que por su abundancia en las colecciones de la Esfera Canbalam ha sido considerada como la cerámica más representativa de la costa noroeste de Campeche y Yucatán.

Ball (1978), fue el primero en observar que durante el Clásico Tardío varios de los sitios de los litorales norte de Campeche y noroeste de Yucatán participaron de un mismo componente de filiación tipológica con las cerámicas procedentes de Tabasco y Campeche. Así, Ball (1978), se refirió a este componente como Esfera Cerámica Canbalam No Designada, cuya Vajilla Celestun roja fue una de las cerámicas representativas, perteneciente a los grupos Nimun y Baca. La tipología formal de ésta Esfera fue posteriormente definida por Jiménez et al. (2006a, 2006b), entre otras cosas, las descripciones acentúan la presencia de vidrio volcánico contenido en las pastas cerámicas de Nimun y Baca (Jiménez et al., 2006b).

En cuanto al origen de su manufactura, existen dos versiones acerca del lugar donde pudieron haber sido producidas las cerámicas Nimun y Baca. La primera versión corresponde a Ball (1978), quien planteó que el área de origen de la Vajilla Celestún fue la costa noroeste de Campeche. Opinión que posteriormente fue compartida por Simmons \& Brem (1979) y Bishop et al. (2006). La segunda versión, de Williams-Beck (1999), con opinión contraria a la primera, contempla la posibilidad de que la cerámica Celestún Roja haya sido producida tierra adentro peninsular. Williams-Beck (1999) propuso tres regiones probables de manufactura en el área maya peninsular: 1) en las zonas costeras, 2) en los Chenes (región oeste de Campeche), y 3) en la región Puuc occidental campechana. Jiménez (2002) en sus investigaciones cerámicas de la costa peninsular, está de acuerdo con las ideas de WilliamsBeck, al opinar que el origen probable de la cerámica Celestún podría estar más relacionado con aquellos grupos humanos asentados para ese entonces, en el interior de la península de Yucatán y no con la gente de la costa de Campeche.

En los estudios cerámicos de la costa, (Bishop et al., 2006; Simmons \& Brem, 1979) se ha acrecentado el interés en saber con qué clase de materias primas se elaboraron las cerámicas Nimun y Baca. La caracterización física de estos materiales es importante para poder corroborar o contrastar las hipótesis planteadas con respecto a los focos de su distribución y manufactura. Donde y como se manufacturaron estos recipientes aún son cuestiones que no son claras (Bishop et al., 2006; Simmons \& Brem, 1979). 


\section{ANTECEDENTES DE INVESTIGACIÓN DE LA VAJILLA CELESTÚN ROJA DE LA COSTA DE CAMPECHE Y YUCATÁN}

Piña (1968) y Ruz (1969) fueron quienes hicieron los primeros reportes detallados de las propiedades físicas de la Vajilla Celestún Roja de la costa se hicieron en Jaina, Champotón, y Los Guarixés. Piña (1968) nombró la cerámica hallada como del tipo café (que corresponden a la tipología Nimun y Baca) y la describió de la siguiente manera: la cerámica del tipo café se caracteriza por tener un barro de textura granulosa, debido al desgrasante de arena, cuarzo o concha marina, en forma de partículas gruesas. Muestra un color rojizo, ocre-amarillento, grisáceo o marrón. Estas coloraciones se deben al cocimiento, el cual varía de malo a regular.

Según Ruz (1969, Figs. XLVII 16-28 y XVLIII 1-74) las cerámicas del tipo café ó ladrillo (Nimun) y rojiza con baño crema (Baca) procedentes de Champotón, Ciudad Campeche y Los Guarixés, tenían una pasta similar y presentan mal cocimiento, así como una textura granulosa, con abundantes fragmentos de desgrasante (partículas de color gris claro y fragmentos cristalinos en los barros oscuros, así como semillas carbonizadas). Por otra parte, a los ejemplares Baca y Nimun de Jaina, (Ruz 1969), los describe con una pasta de textura granular con abundancia de partículas calcáreas, arena y semillas. Ball (1978) hallando diferencias en la textura de la pasta de la Vajilla Celestún Roja, así como abundantes bioclastos (conchas) y otras de color marrón o blanco opaco de naturaleza no determinada.

Simmons \& Brem (1979) investigaron las características petrográficas de las cerámicas procedentes de Yucatán. Su estudio petrográfico abarcó un total de nueve fragmentos procedentes de sitios de tierra adentro yucateca y de la costa de la Quintana Roo (Dzibilchaltún, Chichen Itzá, Muna y Balantun); además presentan mapas de los componentes no plásticos en las cerámicas que incluyen la costa campechana. Simmons \& Brem (1979) indican que la Celestún Roja es notable en la escasez de fragmentos de pómez, vidrios menos complejos y grandes, además de fenocristales y fragmentos de toba. Agregan que los núcleos de fragmentos de tobas fueron reemplazados por calcita microcristalina que borra la textura primaria. Simmons \& Brem (1979), resumen que para el Clásico Tardío, las pastas con cenizas volcánicas están limitadas a los sitios de la costa norte y que esta pasta es diferente de la usada en otras partes.

Simmons \& Brem (1979), con base en la presencia de pómez, fenocristales y tobas halladas en la pasta Celestún Roja, hicieron una diferenciación entre los vidrios de la costa yucateca y los vidrios contenidos en las cerámicas tipo pizarras y en otras vajillas, considerando como los más finos a los vidrios procedentes de sitios del interior de Yucatán. Basándose en el tamaño de los vidrios y el porcentaje de 30,9\%, Simmons \& Brem (1979), plantearon que los clastos de origen volcánico no formaron parte de los constituyentes naturales en las arcillas usadas para la elaboración de los recipientes Nimun y Baca. Simmons \& Brem (1979), argumentaron que las cantidades elevadas de vidrio en las pastas parecen sugerir que, en caso de haber sido importado, se tuvo que haber tenido un sistema de distribución bien organizado y constante para poder cubrir los grandes volúmenes de materia prima que se requerían para la elaboración de los recipientes. La distribución de esta materia prima en la costa de Yucatán quizá estuvo asociada de manera cercana con las mismas redes de intercambio de la obsidiana guatemalteca Simmons \& Brem (1979).

En el área maya se han reportado esquirlas de vidrios volcánicos con presencia de calcita, asímismo, en Uaxactún, Guatemala, se realiza la misma observación, esto es, las cenizas volcánicas gruesas y finas con pómez contienen calcita. Shepard (1964) señala que ésta calcita no rellena los poros o las fracturas de las cerámica, así propuso que las cenizas guatemaltecas con presencia de calcita probablemente fueron obtenidas de una región fluvial y calcárea, como lo son el cinturón de calizas de la Alta Verapaz, en Guatemala, los depósitos ribereños del río Monkey o las calizas de Belice. Por su parte, Simmons \& Brem (1979), tomando como referencia la idea planteada por Shepard (1964), también concibieron la posibilidad de una relación con fuentes guatemaltecas de la región de la Alta Verapaz. Simmons \& Brem (1979), propusieron la posibilidad de que la ceniza de la 
costa de Campeche se pudo haber transportado vía Aguacatal, Campeche, o la región de Trinidad, Chiapas, siendo que al mismo tiempo estos dos lugares se abastecían de fuentes de ceniza volcánica guatemaltecas (Simmons \& Brem, 1979).

También se ha reportado en las cerámicas procedentes de algunos sitios del interior de Yucatán, la aglutinación de materiales que fueron adheridos o entremezclados con la ceniza. Una cuestión de interés primario era saber si el desgrasante de ceniza procedía de una o más fuentes de abastecimiento, por ello Shepard (1964), analizó muestras de Chichen Itzá, Uxmal, Holactún y Oxkintok, señalando que los vidrios no variaron en forma, fineza y asociación con respecto a otros minerales; y algunas pastas cerámicas yucatecas se distinguieron por la presencia de partículas de toba o ceniza endurecida, de coloración naranjaarcillosa, debido a la presencia de arcilla ó de calcita (Shepard, 1964; Smith, 1971). Para Brainerd (1958) esta mezcla de la arcilla de color bayo y esquirlas de vidrio con calcita identificadas por Shepard (1964), parecería ser el resultado de un origen secundario.

\section{ANÁLISIS PETROGRÁFICO DE LA VAJILLA CELESTÚN ROJA DE ASENTAMIENTOS DE LA ESFERA CERÁMICA CANBALAM.}

Basado en que la petrografía cerámica es una técnica arqueológica científica en la que se pueden establecer rasgos que ayuden a interpretar aspectos de la procedencia y tecnología de los artefactos (Rye, 1980; Rands \& Bargielski, 1992; Stoltman, 2001; Riederer, 2004; Maniatis, 2009; Peterson, 2009; Rapp, 2009; Obando et al., 2011; entre otros). Los resultados aquí expuestos, proceden de doce muestras cerámicas de cuatro sitios que se ubican en la costa norte y occidente de la península de Yucatán, México: Jaina, Isla Piedras, Uaymil, Xcambó (figuras 1 y 2).

Se describen todos los componentes minerales (incluyendo los minerales accesorios), así como los aspectos texturales (tamaño y forma) los cuales son atributos petrográficos que han sido considerados importantes en los estudios de caracterización de los vidrios (Shepard, 1939; Shepard, 1964; Jones, 1986; Ford \& Glicken, 1987; Simmons \& Brem, 1979; Ford \& Rose, 1995; Varela \& LeClaire, 1999; Ford y Spera, 2007; Sunahara, 2009; Obando et al., 2011; Gregor et al., 2013).

Las láminas delgadas de la cerámica Nimun y Baca fueron descritas de acuerdo a las siguientes características petrográficas: A) componentes detríticos (silicoclásticos y carbonatados), B) minerales accesorios, C) matriz y D) aspectos texturales.

\section{Cerámica Nimun}

\section{Componentes detríticos (silicoclásticos y carbonatados)}

Los componentes detríticos de las muestras Nimun son fragmentos de rocas volcánicas riolíticas (tobas vitroclásticas), pómez, esquirlas de vidrio, cuarzos y plagioclasas, así como hematita, magnetita y otros menores (figuras 3, 4 y 5).

Los fragmentos de pómez (Fig. 3a, d y e), muestran un porcentaje que oscila entre 2 y $6 \%$ ciento, el promedio es de 3,83\% (Cuadro 1). Se presentan en forma de hilos de vidrio fibrosos, pómez vesicular, fábrica laminar vesicular fina a gruesa con formas ovaladas, angulares a subredondeadas con alta redondez y de baja a alta esfericidad. A veces con impregnaciones de óxidos de hierro. Su tamaño promedio de $0,35 \times 0,117 \mathrm{~mm}$ (arena fina a media), pero se han observado tamaños de hasta $0,60 \times 0,30 \mathrm{~mm}$ (arena media a gruesa) (Cuadro 2).

Los fragmentos de toba (Fig. 4a, d, f), son fragmentos de tobas vitroclásticas a tobas vítreas de composición riolítica, muestran porcentajes entre 5 y $13 \%$ aproximadamente con un promedio de $8,33 \%$ (Cuadro 1). Estas tobas, localmente tienen microlitos de plagioclasa de hasta $0,125 \mathrm{~mm}$, presentan fenocristales de hornblenda basálticas $\mathrm{y}$ algunas veces se pueden observar con microlitos de plagioclasa y biotita. El vidrio contenido en el fragmento, puede ser incoloro, vesicular, representando burbujas de gas fragmentadas, las paredes de estas burbujas pueden tener paredes de hasta $0,05 \mathrm{~mm}$ de grosor (Fig. 4f). 


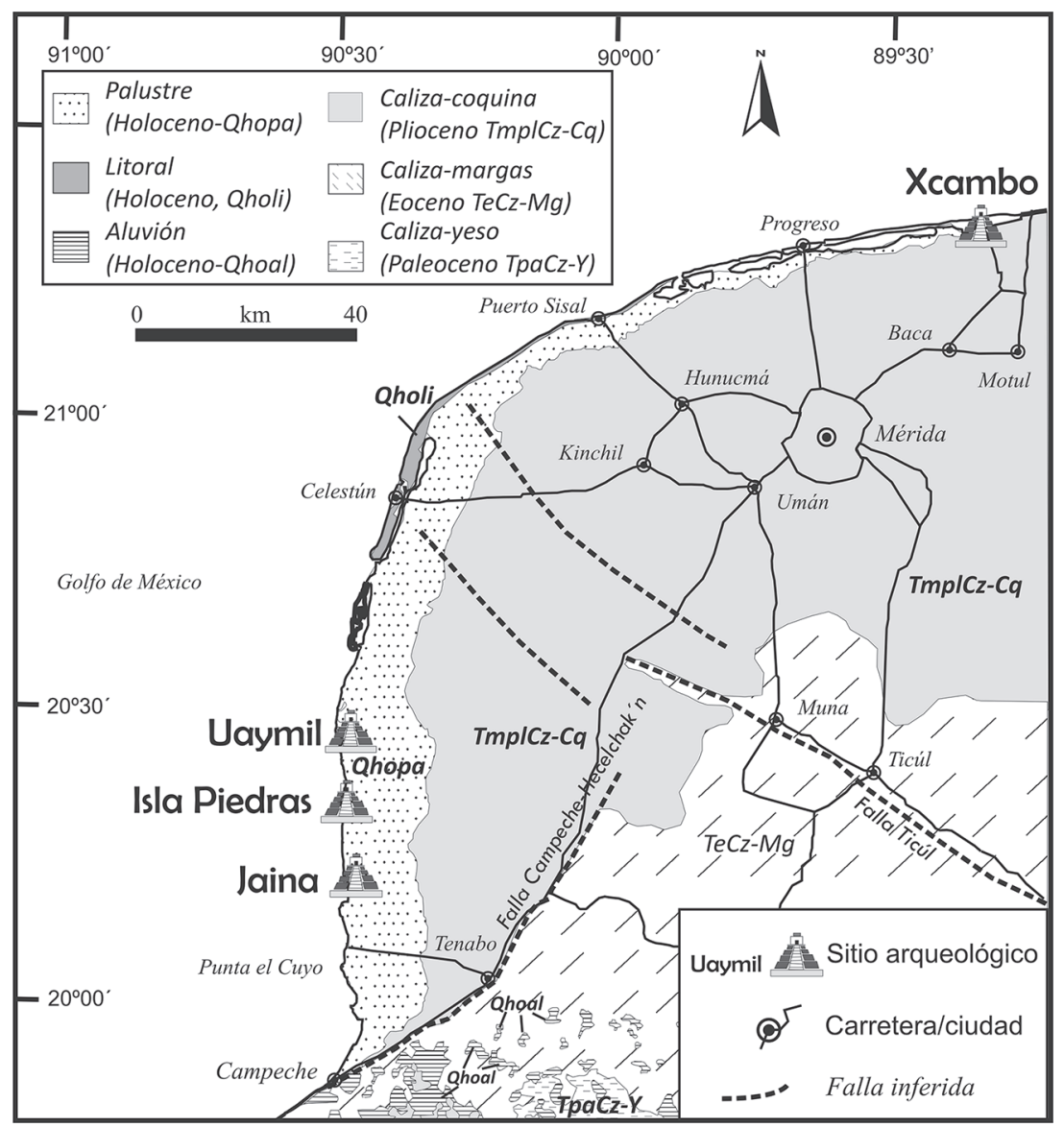

Fig. 1: Mapa de localización de sitios del litoral noroccidente de la península de Yucatán, (base geológica modificada de: SGM,2007).

En la muestra 8040-N (Cuadro 1), se observan fragmentos de tobas vitroclásticas vesiculares (similares a 8034-N y 8005-N), con oxihornblendas, y algunas con cuarzo. Si los fragmentos están meteorizados, pueden observarse totalmente arcillitizados y hematitizados, con microlitos de plagioclasa y biotita sin meteorizar. También ocasionalmente se identificó pómez con impregnaciones de óxidos de hierro y se observan con cristales de calcita (microesparita) como cemento calcáreo secundario.

Respecto a su forma, las tobas vitroclásticas son redondeados, subredondeados, subangulares a angulares, subdiscoidales, de alta esfericidad a baja esfericidad, algunos subprismoidales y subdiscoidales (Fig. 4a, d, f). En cuanto a los tamaños, todos los fragmentos de tobas son de ceniza gruesa, de acuerdo a la clasificación de LeMaitre (1989) y de acuerdo a la escala de Wentworth (1922) son: arena muy gruesa $(2 \times 1$ $\mathrm{mm})$, arena media a gruesa $(0,55 \times 0,2 \mathrm{~mm})$ y arena media $(0,49 \times 0,24 \mathrm{~mm})$. Predominan los fragmentos tamaño arena gruesa.

Las esquirlas vidrio (shards; Fig. 5a,b,c,d), muestran porcentajes entre $8 \%$ y $19 \%$ y el promedio es de $12,33 \%$ (Cuadro 1), son incoloras y transparentes. Bajo el microscopio polarizado, algunas esquirlas se presentan recristalizadas, esto es, presentan una leve birrefringencia. Sus formas pueden ser tipo agujas, horquillas, yunques, tripoides, globulares fragmentadas, esquirlas planas y esquirlas varias, dentro de los vidrios se pueden 


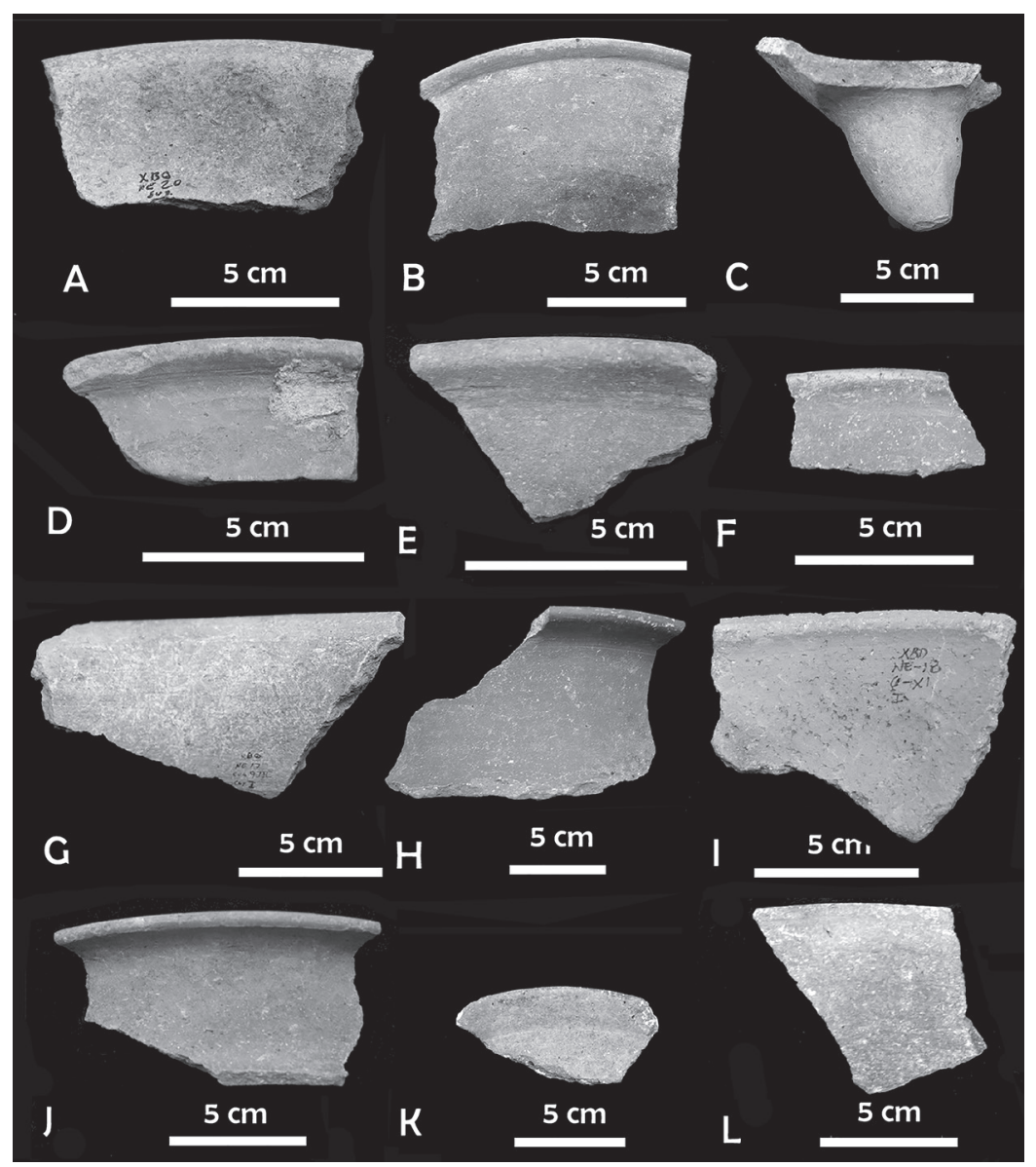

Fig. 2: Cerámica Baca (a-f) y Cerámica Nimun (g-1). a) 8003-B (Xcambó), b) 8006-B (Jaina), c) 8030 (Uaymil), d) 8022-B (Xcambó), e) 8038-B (Isla Piedras), f) 8043-B (Jaina), g) 8005-N (Xcambo), h) 8034-N (Uaymil), i) 8020-N (Xcambó), j) 8033-N (Isla Piedras), k) 8041-N (Jaina), 1) 8040-N (Jaina).

observar típicas microfracturas (por ejemplo Fig. 5 b y $5 d$ ). El grosor de las paredes de las esquirlas puede llegar hasta $0,1 \mathrm{~mm}$ (Cuadro 2, Fig. 5).

El tamaño promedio de las esquirlas es de $0,123 \times 0,043 \mathrm{~mm}$ (arena fina a limo grueso), el máximo es de 0,786x0,206 mm (arena media a gruesa), pero algunos fragmentos pueden llegar hasta $0,5 \times 0,4 \mathrm{~mm}$ (arena gruesa, muestra 8040-N) y el mínimo de $0,017 \times 0,005 \mathrm{~mm}$ (limo muy fino a medio). Las esquirlas de vidrio contenidas en la matriz arcillosa, pueden presentar un alineamiento paralelo.

Los cristales de calcita (Fig. 6a y f), muestran un promedio de $7 \%$, y se presenta como micrita a microesparita equigranular, ocasionalmente se observa esparita (Fig. 6a). Los fragmentos son recristalizados, con óxidos de hierro localmente. También se ha observado, como la calcita ha recristalizado en microgeodas, láminas concéntricas, en hábito acicular y rellenando poros total o parcialmente (Fig. 6).

Es necesario destacar que en las tobas vitroclásticas, se han observado procesos de reemplazo parcial de los vidrios por calcita. Debido a esto último, se interpreta que la calcita es de recristalización secundaria por procesos de meteorización o lixiviación post-enterramiento.

Los cuarzos muestran un porcentaje de 3 a $7 \%$ con un promedio de $4,33 \%$ (Cuadro 1), siempre se presentan sin alteración pero localmente pueden 

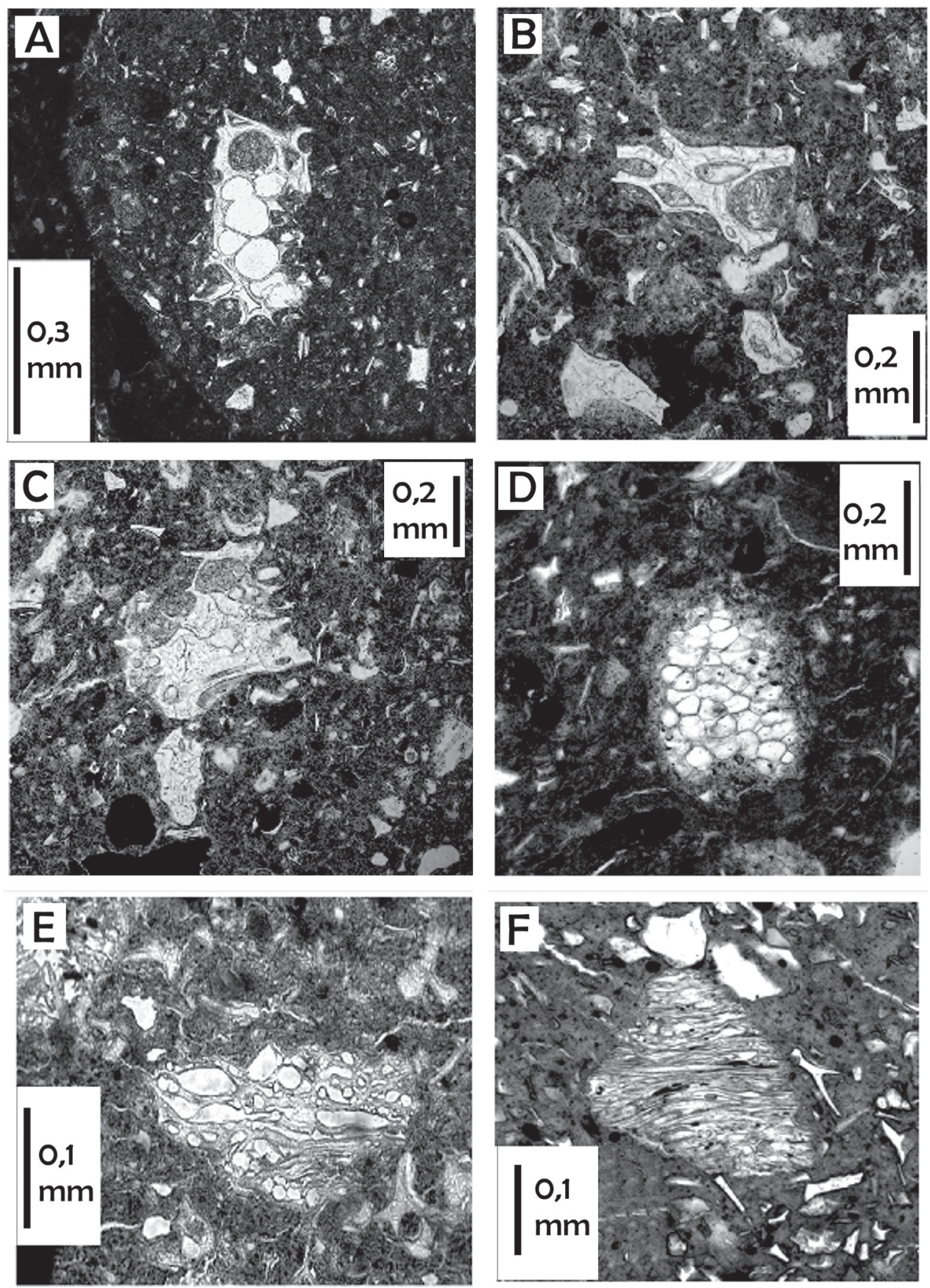

Fig. 3: Fragmentos de pómez, nótese la matriz con numerosas esquirlas de vidrio: a) Pómez con vesículas redondeadas, con relleno parcial arcilloso, b) pómez anastomosada, se muestran paredes gruesas de vesículas rotas, con relleno parcial arcilloso. c) Pómez vesicular de paredes gruesas, con relleno parcial arcilloso. d) Pómez vesicular fina tipo "panal de abeja". e) Pómez vesicular con poros alargados dando una laminación grosera por aplastamiento original natural. f) Pómez laminada con vesículas finas alargadas, evidenciando aplastamiento durante su enfriamiento natural. 

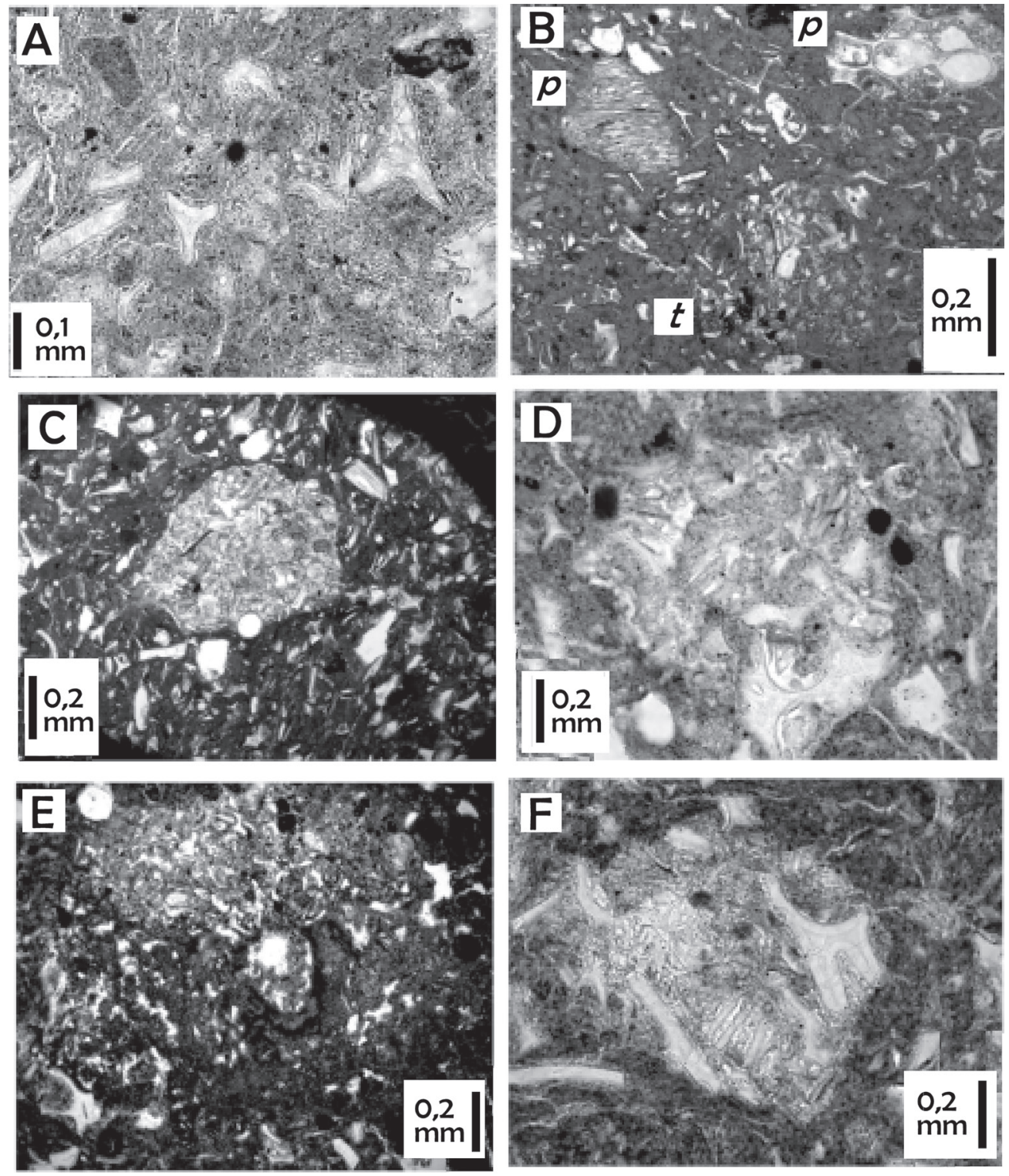

Fig. 4: Tobas vitroclásticas, nótese la matriz con numerosas esquirlas de vidrio: a) Detalle, de fragmentos de tobas vitroclásticas compuesta por fragmentos de vidrio grueso rectangular y tripoidales. b) Clasto de toba vitroclástica (t) rodeada de fragmentos de pómez (p) laminados finos y gruesos vesiculares. c) Clasto de toba vitroclástica, obsérvese la redondez y la alta esfericidad. d) Fragmento subredondeado de toba vitroclástica conteniendo múltiples esquirlas de vidrio grueso. e) Fragmento tobáceo angular conteniendo esquirlas de vidrio fino. f) Fragmento tobáceo subredondeado conteniendo vidrio grueso.

presentarse con impregnaciones de hierro, con extinción ondulante, y hasta disueltos por procesos magmáticos primarios. Son redondeados, subredondeados, subangulares, angulares. Sus tamaños máximos promedio son $0,32 \times 0,14 \mathrm{~mm}$ (arena fina a media) y los mínimos $0,032 \times 0,042 \mathrm{~mm}$ (limo medio), sus formas son subdiscoidales, subprismáticos hasta esféricos. 

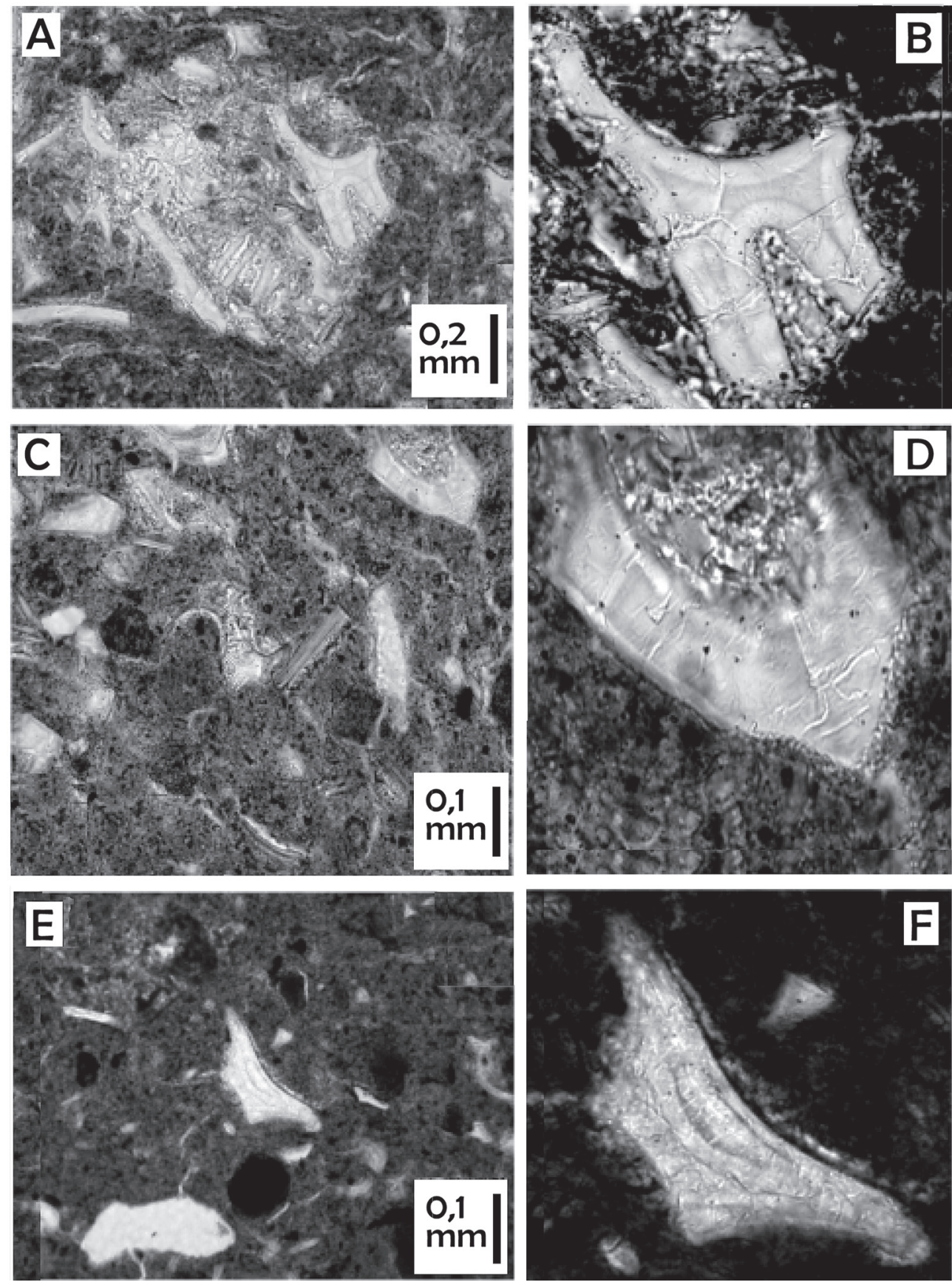

Fig. 5: Esquirlas de Vidrio: en la columna de la izquierda el aspecto general, el detalle se presenta en la columna de la derecha. Todas las esquirla de vidrio representan fragmentos de paredes de vesículas (burbujas de gas aglomeradas). Los detalles de la columna derecha muestran esquirlas laminadas y con fracturas transversales y paredes marcadas, algunas esquirlas muestran recristalización como en el caso e) y f). 
Cuadro 1

Análisis petrográfico semicuantitativo. Porcentaje de componentes detríticos y matriz. Secciones delgadas Nimun

\begin{tabular}{ccccccccccccccccc}
\hline $\begin{array}{c}\text { Muestra } \\
(\%)\end{array}$ & $\begin{array}{c}\text { Tob. } \\
\text { Vitro }\end{array}$ & $\begin{array}{c}\text { Esq. } \\
\text { Vidrio }\end{array}$ & Póm. & $\begin{array}{c}\text { Frag. } \\
\text { Cal }\end{array}$ & $\begin{array}{c}\text { Frag. } \\
\text { Riol. }\end{array}$ & $\begin{array}{c}\text { Q } \\
\text { Poli }\end{array}$ & Plag & Cal & Hem & Mag & $\begin{array}{c}\text { Horn. } \\
\text { Bas }\end{array}$ & Cir & Biot & Ag & Mat \\
\hline $8005-\mathrm{N}$ & 6 & 8 & 2 & - & - & 3 & - & 2 & 4 & 10 & 1 & - & 0,5 & - & - & 64 \\
$8034-\mathrm{N}$ & 5 & 10 & 5 & 7 & - & 4 & 1 & 2 & 5 & 7 & 1 & - & - & - & - & 53 \\
$8020-\mathrm{N}$ & 7 & 12 & 3 & - & - & 5 & - & 1 & 1 & 12 & 1 & 0,5 & - & 1 & 0,5 & 38 \\
$8033-\mathrm{N}$ & 8 & 10 & 3 & - & - & 4 & - & 1 & 25 & 7,5 & 1 & 2 & 0,5 & 1 & - & 37,50 \\
$8041-\mathrm{N}$ & 13 & 15 & 6 & - & - & 3 & 0,5 & 1 & 3 & 3 & 0,5 & 0,5 & 0,5 & 0,5 & 0,5 & 53 \\
$8040-\mathrm{N}$ & 11 & 19 & 4 & - & 7 & 7 & 0,5 & 1 & 4 & 5 & 1 & - & - & 0,5 & 0,5 & 48 \\
Prom. & 8,33 & 12,33 & 3,83 & 1,17 & 1,17 & 4,33 & 0,33 & 1,33 & 7 & 7,42 & 0,92 & 0,50 & 0,25 & 0,50 & 0,25 & 48,92 \\
\hline
\end{tabular}

Tob.Vitro= Toba vitroclástica, Esq.Vidrio=Esquirlas de vidrio, Póm=pómez, Frag.Cal=fragmentos calcáreo, Frag.Riol=fragmentos riolíticos, Q=cuarzo, Q.Poli=cuarzo policristalino, Plag=plagioclasa, Cal=calcita, Hem=hematita, Mag=magnetita, Horn. Bas=hornblenda basáltica, Cir=circón, Biot=biotita, Aug=augita, Mat=matriz., Prom.= promedio

Los cuarzos policristalinos siempre son escasos y no sobrepasan el 1\% máximo aproximadamente, pero en algunas secciones delgadas está ausente, el promedio tan solo llega a $0,33 \%$ (Cuadro 1). Estos cuarzos policristalinos, se presentan con una textura interna de gruesa a fina y los fragmentos se observan en agregados de disposición radial o en abanico. Son detritos con un tamaño máximo de $0,2 \times 0,19 \mathrm{~mm}$ (arena fina a media), y el mínimo de 0,06x0,05 mm (arena muy fina), de baja a alta esfericidad, subredondeados a redondeados, con una forma sub discoidal a esférico.

Las plagioclasas tienen como máximo aproximadamente $2 \%$, el promedio es de $1,33 \%$. En algunos fragmentos el porcentaje de anortita es de $40-50 \%$ (andesina). Se presentan fragmentos angulares con zonación, maclados, subangulares, generalmente sin alteración (Cuadro 1).

La hematita muestra aproximadamente 3 a $10 \%$, promedio $7,42 \%$, es de color rojo, posiblemente fragmentos de roca (Cuadro 1).

\section{Componentes detríticos: Minerales accesorios}

En este trabajo se considera minerales accesorios aquellos que son traza ó por lo general no superan el $1 \%$ ó bien que petrológicamente no son determinantes en la clasificación de rocas
(Cuadro 1), entre ellos están: la magnetita de 0,5 y ocasionalmene al $2 \%$, es un mineral opaco. La augita, subredondeadas. La hornblenda basáltica (oxihornblenda), con pleocroísmo en verde a marrón, sin exfoliación. La biotita, pleocroica en marrón, de aspecto fibroso y dobladas, probablemente por compresión. Estas pueden presentarse meteorizadas, angulares a subredondeadas y el circón de alto relieve y subredondeado (Cuadro 1).

\section{Matriz}

El término matriz se refiere a la arcilla como medio soportante de los granos, expresado en porcentaje por volumen de muestra, petrográficamente es posible observar el grado de filomorfismo, esto es, el contenido de minerales filosilicatados. Esto hace que la matriz adquiera birrefringencia bajo luz polarizada con un grado de filomorfismo de bajo (poco brillante) a alto (muy brillante).

La matriz es de tipo arcillosa, con un promedio de $48,92 \%$, un mínimo de $37,5 \%$ y un máximo de $64 \%$. Los colores a nícoles paralelos son amarillo claro, marrón rojizo a anaranjada. En nícoles cruzados se observa de color marrón-amarillento, rojiza a roja oscura. De filomorfismo bajo, moderado a muy alto. La matriz puede dar un aspecto granular fino desarrollado. 


\section{Cuadro 2}

Tamaño de granos en milímetros, vidrio, pómez y granulometría general. Secciones delgadas Nimun

\begin{tabular}{|c|c|c|c|c|c|c|c|c|c|}
\hline \multirow[b]{2}{*}{ Muestra } & \multicolumn{4}{|c|}{ Tamaño Esquirlas de Vidrio } & \multirow{2}{*}{$\begin{array}{c}\text { Pómez } \\
\text { Tamaños } \\
\text { (mm) }\end{array}$} & \multicolumn{3}{|c|}{ Tamaño Grano } & \multirow[b]{2}{*}{ Notas } \\
\hline & $\begin{array}{l}\text { Promedio } \\
(\mathrm{mm})\end{array}$ & $\begin{array}{c}\text { Máximo } \\
\text { (mm) }\end{array}$ & $\begin{array}{c}\text { Mínimo } \\
(\mathrm{mm})\end{array}$ & $\begin{array}{c}\text { Grosor } \\
\text { paredes }(\mathrm{mm})\end{array}$ & & $\begin{array}{c}\text { Promedio } \\
(\mathrm{mm})\end{array}$ & $\begin{array}{l}\text { Máximo } \\
(\mathrm{mm})\end{array}$ & $\begin{array}{c}\text { Mínimo } \\
(\mathrm{mm})\end{array}$ & \\
\hline $8005-\mathrm{N}$ & $0,12 \times 0,07$ & $0,33 \times 0,16$ & $0,029 \times 0,005$ & 0,04 & $0,38 \times 0,16$ & $0,20 \mathrm{x} 0,125$ & $2,05 \times 1,5$ & $0,005 \times 0,0025$ & - \\
\hline $8034-\mathrm{N}$ & $0,075 \times 0,045$ & $0,41 \times 0,3$ & $0,012 \times 0,005$ & - & $0,1 \times 0,065$ & $0,17 \times 0,15$ & $1,95 \times 1,37$ & $0,01 \times 0,02$ & $\begin{array}{l}\text { tamaño } \\
\text { seriado }\end{array}$ \\
\hline $8020-\mathrm{N}$ & $0,24 \times 0,06$ & $0,4 \times 0,07$ & $0,015 \times 0,003$ & - & $0,2 \times 0,007$ & $0,25 \times 0,17$ & $1,37 \times 1,12$ & $0,0025 \times 0,0037$ & - \\
\hline $8033-\mathrm{N}$ & $0,08 \times 0,015$ & $0,4 \times 0,1$ & $0,015 \times 0,0075$ & - & $0,60 \times 0,30$ & $0,3 \times 0,375$ & $1,80 \times 0,95$ & $0,003 \times 0,005$ & - \\
\hline $8041-\mathrm{N}$ & $0,07 \times 0,03$ & $0,32 \times 0,21$ & $0,012 \times 0,005$ & 0,03 a 0,1 & $0,17 \times 0,35$ & $0,3 \times 1,75$ & $2,29 \times 0,9$ & $0,00275 \times 0,025$ & - \\
\hline $8040-\mathrm{N}$ & $0,15 \times 0,04$ & $0,5 \times 0,4$ & $0,018 \times 0,0032$ & - & $0,65 \times 0,17$ & $0,37 \times 0,35$ & $1,97 \times 1,22$ & $0,0025 \times 0,005$ & - \\
\hline Prom. & $0,123 \times 0,043$ & $0,78 \times 0,20$ & $0,017 \times 0,005$ & - & $0,35 \times 0,117$ & $0,265 \times 0,486$ & $1,90 \times 1,17$ & $0,004 \times 0,0102$ & - \\
\hline
\end{tabular}

Prom.: Promedio

La fábrica por lo general es reticulada o bien levemente alineada paralelamente, con granos sin orientación hasta ligeramente orientados.

\section{Aspectos texturales.}

En este trabajo, para identificar el tamaño de los clastos no arcillosos, se usa la escala de Wentworth (1922) esto debido a que describe un mayor rango de granulometrías. Se amplía la descripción con los criterios de selección granulométrica y tipo de contactos de los detritus.

Tamaño máximo de grano: en dependencia de la sección delgada, los tamaños máximos son reportados como grava muy fina, gránulos muy finos, arena gruesa a muy gruesa.

Tamaño mínimo de grano: limo muy fino a medio hasta arcilla gruesa.

Tamaño de grano promedio: oscila entre arena fina a media gruesa, sin embargo, en una misma cerámica el tamaño puede ser seriado (muestra 8034-N, Cuadro 2).

Selección de los granos: desde muy mal seleccionada a pobremente seleccionada.

Forma de los granos: puede ser elipsoidal, esférica, prismática, discoidal, con una redondez de los granos de alta a baja esfericidad y desde muy angulosos a bien redondeados.
Tipo de contactos: Los contactos en su mayoría son flotantes: $98 \%$ y de tipo punto: $2 \%$, lo cual indica que están rodeados por la matriz arcillosa.

\section{Cerámica Baca}

Componentes detríticos (silicoclásticos y carbonatados)

Los componentes silicoclásticos de las muestras Baca son similares a los de la cerámica Nimun, es decir, también se observaron fragmentos de roca volcánica tanto riolíticos como andesíticos, tobas vitroclásticas, pómez, esquirlas de vidrio, cuarzos, plagioclasas, calcita, hematita y otros menores (Cuadro 3).

Los fragmentos de toba (Figura $4 b, c)$, muestran porcentajes que oscilan entre 2 y $12 \%$, aproximadamente con un promedio de $7,67 \%$. Son fragmentos de tobas vitroclásticas a tobas vítreas de composición riolítica con cuarzo, biotita y vidrio, oxidadas y arcillitizadas, conteniendo restos de hornblenda basáltica (oxihornblenda). El vidrio de los fragmentos es incoloro sin alteración visible y con microesparita secundaria.

En el caso del preparado 8022-B, las tobas vítreas tienen matriz arcillosa, marrón- amarillento a claro (Figura $4 b, c)$. 

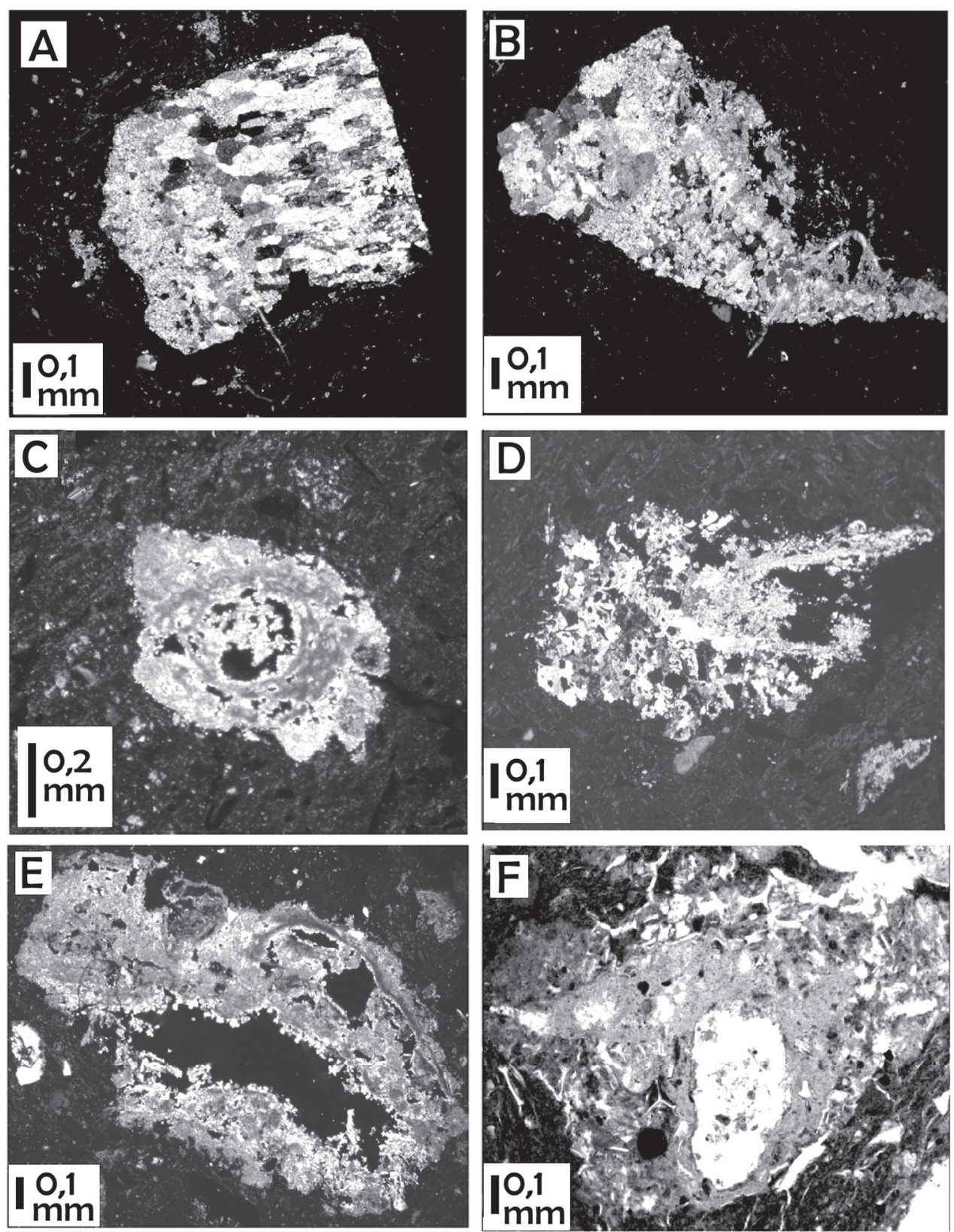

Fig. 6: Calcita recristalizada: a) Esparita con fábrica laminada y hábito prismático. b) Esparita y microesparita, nótese que la esparita se encuentra en el centro y la microesparita tiende a concentrarse como una película en el borde. c) relleno de poro, con cristalización inicial de micrita concéntrica, culminando la cristalización, con calcita fibrosa muy fina. d) Toba vitroclástica con cemento calcáreo secundario, el cual invade los fragmentos y los reemplaza parcialmente con micrita y microesparita. e) relleno de poro, microgeoda: películas de micrita, microesparita, se observan al menos dos generaciones de calcita, la última generación representa cristales aciculares de calcita, cementan fragmentos de vidrios, observándose un reemplazo parcial. f) relleno de poro, películas de micrita que a su vez engloban esquirlas de vidrio reemplazándolas parcialmente. 
Cuadro 3

Análisis petrográfico semicuantitativo. Porcentaje de componentes detríticos y matriz. Secciones delgadas Baca

\begin{tabular}{|c|c|c|c|c|c|c|c|c|c|c|c|c|c|c|c|c|c|c|}
\hline $\begin{array}{c}\text { Muestra } \\
(\%)\end{array}$ & $\begin{array}{c}\text { Tob. } \\
\text { Vt }\end{array}$ & $\begin{array}{l}\text { Esq. } \\
\text { Vid }\end{array}$ & Póm & Fg.Riol. & Fg.And & $\mathrm{Q}$ & Q.Poli & Plag & Cal & Hem & Mag & $\begin{array}{l}\text { Horn. } \\
\text { Bas }\end{array}$ & $\begin{array}{l}\text { Horn. } \\
\text { Verde }\end{array}$ & Cir & Biot & Aug & Epi & Mat \\
\hline 8003-B & 12 & 13 & 2 & 2 & - & 3 & 2 & 1 & 1 & 7 & 1 & 1 & - & - & 0,5 & - & 0,5 & 55 \\
\hline 8006-B & 10 & 18 & 2 & - & - & 5 & 1 & 1 & 1 & 2 & 1 & - & - & 0,5 & - & - & - & 59 \\
\hline 8030-B & 8 & 13 & 4 & 1 & - & 3 & 1 & 1.5 & - & 6 & 1 & - & 0,5 & 0,5 & 1 & - & 0,5 & 60,5 \\
\hline 8022-B & 6 & 25 & 2 & - & - & 3 & 1 & 1 & 10 & 6 & 1 & 1 & - & - & 0,5 & 0,5 & 0,5 & 44 \\
\hline 8038-B & 8 & 22 & 5 & - & 0.5 & 6 & 1 & 4 & 12 & 1 & 1 & - & 1 & 0,5 & 1 & 0,5 & - & 38 \\
\hline 8043-B & 2 & 7 & 4 & 0.5 & - & 4 & 1 & 1 & 13 & 8 & 0,5 & 0,5 & - & 0,5 & 1 & - & - & 59 \\
\hline Prom. & 7,67 & 16,33 & 3,17 & 0,58 & 0,08 & 4 & 1,17 & 1,58 & 6,17 & 5 & 0,92 & 0,42 & 0,25 & 0,33 & 0,67 & 0,17 & 0,25 & 52, \\
\hline
\end{tabular}

Tob.Vt= Toba vitroclástica, Esq.Vid=Esquirlas de vidrio, Póm=Pómez, Fr.Riol=fragmentos riolíticos, Fg.And=fragmentos andesíticos, Q=cuarzo, Q.poli=cuarzo policristalino, Plag=plagioclasa, Cal=calcita,Hem=hematita, Mag=magnetita, Horn. Bas=hornblenda basáltica, Horn.Verde=hornblendaverde, Cir=circón, Biot=biotita, Aug=augita, Epi=epidota, Mat=matriz., Prom. $=$ Promedio

En algunas pocos preparados aparecieron fragmentos de roca tipo andesíticos y riolíticos(?), Los fragmentos andesíticos son traza, éstos tienen microlitos de plagioclasa con hábitos prismático corto (rasgo poco común). Los fragmentos riolíti$\cos ($ ?) desde trazas hasta un $2 \%$; estos fragmentos pueden estar muy meteorizados y oxidados, con microlitos de plagioclasa y cuarzo.

Las esquirlas de vidrio (Fig. 5e,f), tienen un porcentaje aproximado de 7 a $25 \%$, el promedio es de $16,33 \%$ y se presentan recristalizadas, transparentes, muy límpidas y sin alteración arcillosa ó carbonatada visible. Con formas variadas de tipo yunques, tripoidales, globulares fragmentadas y en esquirlas varias. Por lo general, los vidrios se observan microfracturados (Fig. 5f). El promedio del tamaño máximo es de 0,440x0,112 mm, (arena media a fina), el tamaño mínimo es de $0,014 \times 0,00415 \mathrm{~mm}$ (limo medio), por último el tamaño del grano promedio es de $0,143 \times 0,039$ $\mathrm{mm}$ (arena fina).

La pómez (Fig. 4b,c,f), muestra un porcentaje de 2 a $5 \%$, el promedio es de $3,17 \%$, con dimensiones promedio de $0,258 \times 0,163 \mathrm{~mm}$ (arena media) (cuadros 3 y 4). Los clastos son fibrosos y vesiculares, localmente se presentan con amígdalas rellenas de arcilla.
Los cuarzos muestran aproximadamente un 3 a $6 \%$. Son fragmentos muy angulares, angulares a redondeados y algunos tienen extinción ondulante. Otros son cuarzos son clastos con textura poikiloblástica con inclusiones de sericita y muscovita y se pueden observar algunos fragmentos con impregnaciones de óxidos de hierro. El tamaño máximo es de $0,24 \times 0,19 \mathrm{~mm}$ (arena media) con un mínimo de $0,05 \times 0,027 \mathrm{~mm}$ (limo medio a grueso), de formas subdiscoidales a prismáticas de baja esfericidad y sub redondeados.

Los cuarzos policristalinos son detritos escasos, su valor máximo es de aproximadamente $2 \%$ (Cuadro 3 ) y pueden presentarse con textura interna fina a gruesa y muy fibrosas. En una de las láminas delgadas se observó un grano con textura "tipo veta de cuarzo". El tamaño máximo es de $0,75 \times 0,46 \mathrm{~mm}$ (arena media), con un mínimo de $0,087 \times 0,067 \mathrm{~mm}$ (arena muy fina), de formas subprismáticas a esféricas de alta esfericidad a baja y subredondeados a angulares.

Las plagioclasas muestran de 1 a $4 \%$ aproximadamente, son macladas con zonación, sin alteración. Algunos fragmentos tienen impregnación de óxidos de hierro, localmente con inclusiones de sericita.

La calcita (Fig. 6b,c,d,e), de 1 a 13\% aproximadamente con un promedio de $6,17 \%$. Este 
mineral presenta micríticas, microesparíticas y esparíticas recristalizadas de origen secundario. En la muestra 8043-B, se aprecian poros rellenos (amígdalas) con anillos concéntricos de crecimiento micrítico a microesparítico (Fig. 6c, e). Se destaca que solo las muestras 8022-B, 8038-B y 8043-B son las únicas que presentan calcita en abundancia (Cuadro 3).

La hematita de 1 a $8 \%$ aproximadamente, el promedio es de $5 \%$, son de color rojo, localmente con laminación burdas.

\section{Componentes detriticos : Minerales accesorios}

Como ya se explicó anteriormente, en este trabajo se consideran minerales accesorios aquellos que son traza ó por lo general no superan el $1 \%$ ó bien que petrológicamente no son determinantes en la clasificación de rocas, entre ellos están (véase Cuadro 3): la augita en trazas, sin meteorización; la hornblenda basáltica de $1 \%$, marrón, con pleocroísmo; la hornblenda verde en trazas, color verde, con pleocroísmo; la biotita en trazas, con pleocroísmo en marrón típico; la epidota en traza, con pleocroísmo en verde claro; circón en trazas, mineral relativamente común en las secciones de Baca; la magnetita es un mineral opaco.

\section{Matriz}

La matriz es de tipo arcillosa, el promedio es de $52,58 \%$, el mínimo es de $38 \%$ y un máximo de $60,5 \%$ aproximadamente (Cuadro 3). Los colores a nícoles paralelos son de marrón claro amarillento a rojiza, rojiza oscura, mientras que los colores de birrefringencia son amarillo claro, marrón-rojiza a un amarillo claro levemente.

En algunos casos la matriz es granular fina desarrollada, pero puede ser posible observar una matriz granular fina poco desarrollada. Con un filomorfismo de bajo a muy alto y una fábrica reticulada,. Localmente se observan bandas discontinuas de arcilla. Los componentes detríticos no presentan orientación.

\section{Aspectos texturales}

La textura general de las muestras involucra el tamaño (Cuadro 4), de acuerdo a la escala de Wentworth (1922), se incluye además la selección y el tipo de contactos:

Tamaño máximo de grano: en dependencia de la sección delgada el tamaño del grano máximo es de arena muy gruesa hasta arena gruesa.

Tamaño mínimo de grano: limo muy fino a medio hasta arcilla gruesa.

Tamaño de grano promedio: va desde arena fina a media.

Selección: desde muy pobremente seleccionada a pobremente seleccionada.

Forma de los granos: elipsoidal, prismática hasta esféricos, con una esfericidad de los granos desde alta esfericidad a baja esfericidad y desde muy angulosos subangulosos, hasta bien redondeados.

Tipo de contactos: flotantes: $99 \%$ y de tipo punto: $1 \%$, lo cual indica que están rodeados por la matriz arcillosa.

\section{LA CALCITA Y LOS PROCESOS DE DIAGÉNESIS}

Con el nombre de diagénesis se denomina el conjunto de procesos físicos y químicos que transforman los sedimentos en rocas sedimentarias. Estos procesos se inician inmediatamente después del depósito (sedimentos blandos recién depositados) y se acentúan durante el enterramiento del sedimento por nuevos sedimentos, de manera que el progresivo incremento de presión (compactación por carga litostática) y temperatura (grado geotérmico) son las causas principales (Vera, 1994). Las zonas principales diagenéticas, entre otras, están la zona vadosa, aguas meteóricas, aguas freáticas, etc, (Ahr, 2008). Entre los primeros $1 \mathrm{a} 2 \mathrm{~m}$, se realizan los procesos de neoformación de minerales (recristalización e inversión mineralógica) bajo condiciones oxidantes o neutras (Folk, 1974; Bathurst, 1975; Corrales et al., 1977; Ahr, 2008; Walther, 2009), por ejemplo, durante el enteramiento, es común la filtración de soluciones saturadas calcáreas que percolan desde la superficie, 
Cuadro 4

Tamaño de granos en milímetros, vidrio, pómez y granulometría general. Secciones delgadas Baca

\begin{tabular}{|c|c|c|c|c|c|c|c|c|}
\hline \multirow[b]{2}{*}{ Muestra } & \multicolumn{3}{|c|}{ Tamaño Esquirlas de Vidrio } & \multirow{2}{*}{$\begin{array}{l}\text { Pómez } \\
\text { Tamaño } \\
\text { (mm) }\end{array}$} & \multicolumn{3}{|c|}{ Tamaño del Grano } & \multirow[b]{2}{*}{ Notas } \\
\hline & $\begin{array}{l}\text { Promedio } \\
(\mathrm{mm})\end{array}$ & $\begin{array}{l}\text { Máximo } \\
(\mathrm{mm})\end{array}$ & $\begin{array}{l}\text { Mínimo } \\
(\mathrm{mm})\end{array}$ & & $\begin{array}{l}\text { Promedio } \\
(\mathrm{mm})\end{array}$ & $\begin{array}{l}\text { Máximo } \\
(\mathrm{mm})\end{array}$ & $\begin{array}{l}\text { Mínimo } \\
(\mathrm{mm})\end{array}$ & \\
\hline 8003-B & $0,1 \times 0,022$ & $0,52 \times 0,12$ & $0,015 \times 0,0025$ & $0,16 \times 0,097$ & $0,2 \times 0,22$ & $1,52 \times 1,25$ & $0,003 \times 0,0037$ & \\
\hline 8006-B & $0,1 \times 0,02$ & $0,25 \times 0,03$ & $0,022 \times 0,01$ & $0,17 \times 0,30$ & $0,22 \times 0,15$ & $1,25 \times 0,6$ & $0,027 \times 0,0027$ & \\
\hline 8030-B & $0,11 \times 0,03$ & $0,45 \times 0,1$ & $0,01 \times 0,0037$ & $0,12 \times 0,11$ & $0,55 \times 0,3$ & $1,25 \times 0,92$ & $0,01 \times 0,015$ & \\
\hline 8022-B & $0,08 \times 0,02$ & $0,350 \times 0,04$ & $0,012 \times 0,0025$ & $0,250 \times 0,08$ & $0,25 \times 0,32$ & $1,05 \times 0,82$ & $0,0075 \times 0,005$ & \\
\hline 8038-B & $0,26 \times 0,08$ & $0,57 \times 0,27$ & $0,005 \times 0,0037$ & $0,46 \times 0,22$ & $0,45 \times 0,28$ & $1,8 \times 0,8$ & $0,0025 \times 0,0037$ & \\
\hline 8043-B & $0,21 \times 0,06$ & $0,5 \times 0,11$ & $0,02 \times 0,0025$ & $0,39 \times 0,17$ & $0,27 \times 0,17$ & $1,8 \times 1,37$ & $0,0025 \times 0,0037$ & $\begin{array}{l}\text { tamaño } \\
\text { seriado }\end{array}$ \\
\hline Prom. & $0,143 \times 0,039$ & $0,44 \times 0,112$ & $0,014 \times 0,00415$ & $0,258 \times 0,163$ & $0,323 \times 0,24$ & $1,445 \times 0,96$ & $0,0087 \times 0,0056$ & \\
\hline
\end{tabular}

Prom. $=$ Promedio

seguido por la recristalización de calcita secundaria (Bathurst, 1975; Ahr, 2008; Durand et al., 2010). Por recristalización se entiende el crecimiento de ciertos cristales a expensas directas de cristales de la misma especie, pero más pequeños (Folk, 1974; Bathurst, 1975 ).

Los procesos de disolución de granos están determinados por la composición de los granos minerales y la química del agua en los poros. Los carbonatos aumentan la solubilidad con el aumento de la acidez, lo que conlleva al relleno de poros por precipitación dando así una cristalización con una variedad de formas individuales, tales como agregados radiales, aciculares, microesparita laminada, micrita masiva (Folk, 1974; Bathurst, 1975; Ahr, 2008; Nichols, 2009; Durand et al., 2010), la neoformación de cristales conlleva a una cementación y por tanto una reducción ó destrucción significativa de la porosidad por una cementación pasiva (Bathurst, 1975; Moore, 1997).

En los preparados de Nimun y Baca, se ha observado calcita con algunas formas y agregados anteriormente descritos, esto es, agregados radiales y aciculares, micrita laminada o burdamente laminada, anillos concéntricos de crecimiento micrítico a micrítico difuso, microesparítico, esparita en prismas elongados, drusas (Figura 6). Todo esto ocasiona un relleno total o parcial de los poros. Ocasionalmente en estos poros rellenos (amígdalas), se puede observar una microlaminación de la cementación, esto es, gradación granulométrica de carbonato, iniciando a partir de las paredes del poro, con una película de micrita que grada a microesparita hacia el centro de la amígdala y se ha observado cómo, en los rellenos parciales de poros la cristalización finaliza con agujas muy finas de calcita (drusas y microgeodas) (Figura 6c y e). Por último, la micrita puede englobar e invadir los fragmentos de roca y las tobas vitroclásticas reemplazando total o parcialmente las esquirlas de vidrio volcánico.

Si se considera que los fragmentos cerámicos han sido enterrados, entonces esto implica que casi de inmediato, los procesos iniciales de la diagénesis se iniciaron. Tales estadios conllevan a formarse calcita con sus variedades, así como el lento reemplazo de vidrios por calcita (Fig. 6c, e y f). La invasión de calcita en poros y clastos, no es más que el proceso normal de lixiviación de sustancias carbonatadas, esto es, percolación de soluciones carbonatadas desde los niveles más altos del suelo.

La presencia de carbonatos es común en los suelos, máxime si son suelos derivados de carbonatos como los de Yucatán y el Petén (Guatemala) y áridos a semiáridos. Dado lo anterior, la calcita secundaria (lixiviada) puede ocurrir en cualquier región ya que es propio de la formación de suelos, siendo así, no es dable tomar 
las calcitas lixiviadas, como indicador para interpretar correlaciones cerámicas de sitios arqueológicos basados en este rasgo, ya que el mismo es totalmente aleatorio y de carácter secundario no ligado a la pasta cerámica original. Por último, se hace notar que se ha producido un claro relleno de poro, lo que significa que la porosidad inicial ya se perdió, y que los efectos de la compactación típico de cargas litostáticas (diagénesis mecánica) son desconocidos.

\section{ASPECTOS DE MANUFACTURA}

Se destacan dos rasgos importantes relacionados con la manufactura de los bordes: a) fracturas por tensión y b) alineación de los filosilicatos.

a) Fracturas por tensión: En el fragmento 8005-N (Nimun) se observó un fracturamiento abierto justo en la curvatura de la zona convexa (CVX, Fig. 7), microscópicamente, la matriz presenta una fábrica evidentemente alineada y microfracturas abiertas (Fig. 7A y 7B).

La figura 7A muestra una microfotografía de la pasta, en donde se observa una microfractura abierta por tensión (Fig. 7A: fT). Tal fractura puede tener un espesor que oscila entre 0,1 $\mathrm{mm}$ y $0,2 \mathrm{~mm}$. Asimismo, asociadas a la fractura principal $\mathrm{fT}$, se encuentran las fracturas secundarias $\mathrm{fa}, \mathrm{fb}, \mathrm{fc}$, las cuales teóricamente tienen el movimiento señalado en la figura $7 \mathrm{~B}$. Microscópicamente, el preparado muestra las fracturas secundarias, que localmente se observan como una pequeña línea casi difusa. Este tipo de rasgo se conoce como microfracturas por tensión, o bien, microfracturas tensionales.

Respecto a la interpretación, dichas microfracturas pudieron ser creadas durante el proceso de manufactura del objeto cerámico, es decir, se generó una compresión del lado cóncavo (CON, Fig. 7A) durante el doblamiento de la pasta cerámica para crear el borde; así, simultáneamente se causó tensión del lado convexo (CVX, Fig. 7A). Esta concentración de esfuerzos pudo haber creado la fractura principal (fT) y sus fracturas secundarias asociadas (fa, fb, fc, Fig.7B). El movimiento señalado por las flechas es tan sólo teórico y no es evidente en la pasta. Lo anteriormente expuesto parece indicar que la arcilla no estaba consolidada aún y que posiblemente el alfarero no utilizó mucha agua para su mezcla, o quizá la pasta estaba casi seca. Fue durante el proceso de desbaste y pulido de la sección delgada que la fractura fue resaltada y evidenciada en la pasta.

b) Alineación de los filosilicatos: La muestra cerámica $8040-\mathrm{N}$ es el borde curvado de un artefacto cerámico que corresponde a un fragmento de cazuela (Figura 8A, nícoles cruzados). El estudio petrográfico en nícoles cruzados mostró una notable alineación paralela (fábrica) de los filosilicatos de la pasta cerámica (Fig. 8B, Fr1, Fr2). Nótese en la Figura 8 que la fábrica paralela está localizada en sitios muy específicos (Figura 8B, Fr1, Fr2). Este rasgo corresponde con una alineación de filosilicatos. El hecho de que se observen dos fábricas muy localizadas (Fig. 8B), que van desde el lado externo del borde (CON) hasta su centro, hace pensar que durante el modelado del borde la pasta, ésta fue sometida a compresión (dirección Co en la figura 8B); tal acción posiblemente alineó los minerales de arcilla, los cuales, al ocurrir el proceso de cocción, preservaron la alineación de filosilicatos. Debido a lo anterior, no es posible pensar que la manufactura del borde fue independiente del cuello, ya que las fábricas Fr1 y Fr2 (Fig. 8B) no continúan hasta el otro extremo del fragmento. Por tanto, se concluye que el borde fue creado por modelación de la arcilla a partir las paredes del artefacto.

\section{GRÁFICOS COMPARATIVOS}

Comparando los gráficos (figuras 9a y $9 \mathrm{~b}$, 10 a y 10 b y Cuadros $1,2,3,4$ ) de Nimun y Baca, ambas cerámicas muestran una textura similar en la pasta. Estos resultados parecen indicar que en la preparación de las arcillas, se tuvo un conocimiento similar en ambos grupos cerámicos. Entonces, quizá las diferencias entre los grupos cerámicos de la Vajilla Celestún Roja están más 


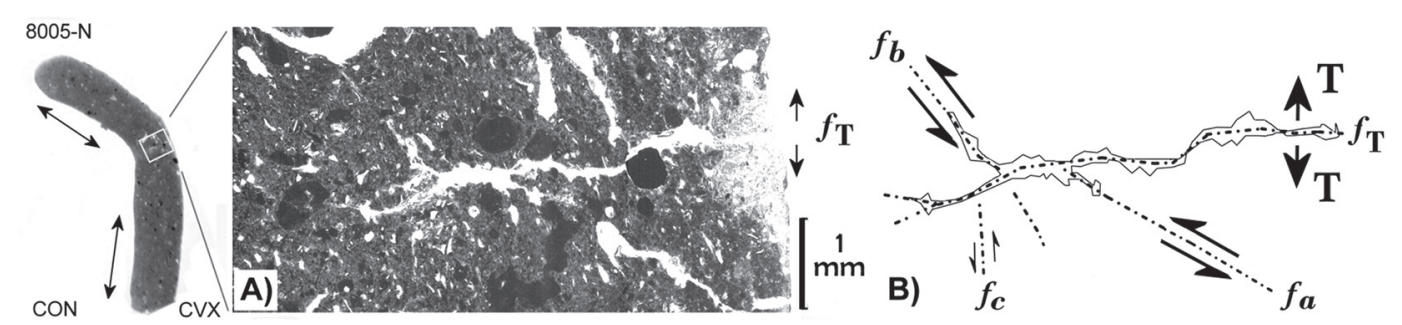

Fig. 7: Representa el preparado 8005-N con una zona de microfracturación principal (fT) y sus microfracturas asociadas. Lado cóncavo (CON), lado convexo (CVX), el alineamiento de la fábrica paralela, es indicado por la doble flecha en el lado CON. A) Se muestra la fractura principal abierta por tensión (fT). B) Esquema mostrando las fracturas observadas (fa,fb,fc), en la cerámica asociadas a la tensión (fT) ocurrida por procesos de manufactura. Las flechas sencillas indican movimiento relativo.

relacionadas con la estética y funcionalidad del tratamiento de la superficie, así como con las formas de vasijas y funciones de uso particulares.

Nimun de color marrón tiene una apariencia visual de mucha porosidad y agrietamiento en su superficie en tanto que Baca muestra un baño (wash) de color crema poco adherido a la superficie. Los estudios tipológicos señalan que en Nimun se hicieron más ollas y cuencos en tanto que en Baca se hicieron más cajetes trípodes. Las cazuelas caracterizan a ambos grupos cerámicos. Los resultados petrográficos del análisis de la pasta de Nimun y Baca indican lo siguiente:

En cuanto a los porcentajes de tobas vitroclásticas, los promedios son de 8,33\% y 7,67\%, la diferencia es de tan solo $0,66 \%$ (compárese cuadros 1 y 3 ).

Las esquirlas de vidrio son incoloros, transparentes, en su mayoría sin alteraciones. En Nimun llegan a 12,33\% mientras que en Baca son de $16,33 \%$, la diferencia es de tan solo $4 \%$.

En cuanto a la pómez Nimun muestra 3,83\% mientras que en Baca es de $3,17 \%$, la diferencia es de tan solo $0,66 \%$.

El cuarzo en Nimun es de $4,33 \%$, pero en Baca es de $4 \%$, la diferencia no es más de $0,33 \%$.

En ambas cerámicas las esquirlas de vidrio son partículas preponderantes, de un tamaño promedio de arena fina y el tamaño de la pómez es arena media.

En ambas cerámicas la matriz muestra un aspecto granular fino desarrollado, con abundancia de minerales opacos. Los cuarzos y las plagioclasas son minerales poco abundantes. Los colores de la matriz con nícoles paralelos muestran rangos de colores entre amarillo, marrón, anaranjado a marrón claro a rojizo oscuro.

\section{CONCLUSIONES GENERALES}

Con una descripción geológica puntualizada de la petrografía de la Vajilla Celestún Roja, se describe por primera vez la tipología Nimun y Baca, como aporte a la definición formal de la llamada Esfera Cerámica Cambalan definida por Jiménez 2002, Jiménez et al., (2006). De un modo supuesto y con base en la distribución regional abundante de los materiales más que en la misma caracterización de la cerámica se han propuesto dos regiones acerca del origen de la manufactura de la cerámica Nimún y Baca. Estas regiones son: la costa de Campeche y la región de los "Chenes" y el "Puuc" que se localizan tierra adentro de la península de Yucatán.

Por otra parte, como se manufacturaron estos recipientes aún son cuestiones que no son claras; sin embargo, en algunos de los estudios cerámicos de la costa, (Bishop et al., 2006; Simmons \& Brem, 1979; Jiménez et al., 2006a) se han interesado en la caracterización de estas cerámicas con la finalidad de saber con qué clase de materias primas se elaboraron las cerámicas Nimun y Baca. En los primeros reportes, antes de ser definida la esfera Canbalam, se les describió macroscópicamente con una textura granular, con abundantes 


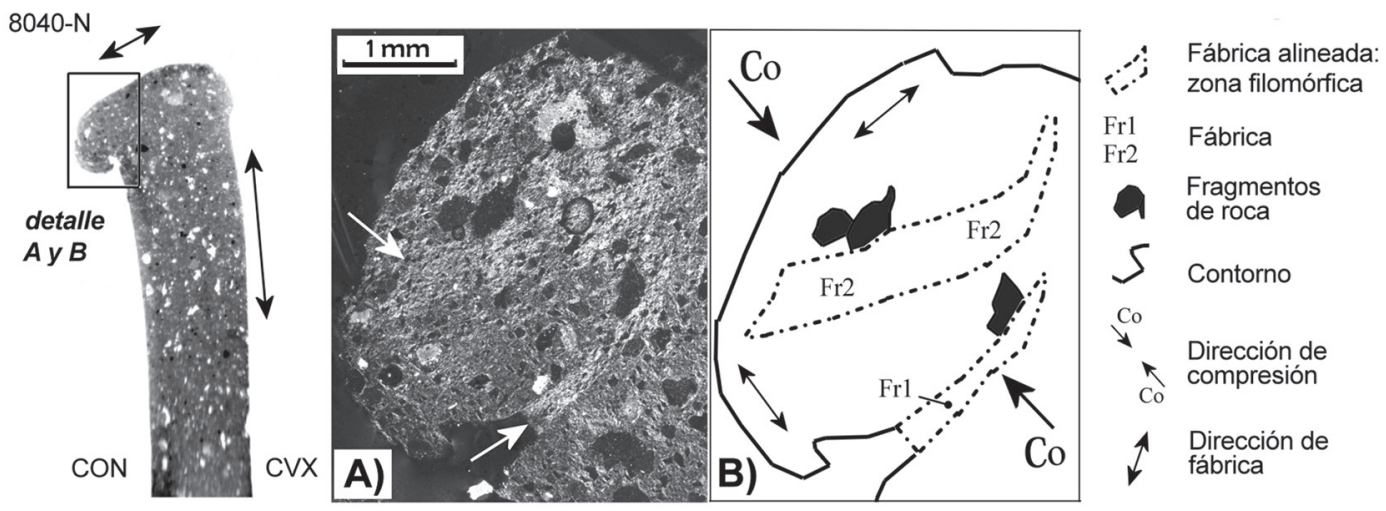

Fig. 8: Borde del fragmento cerámico 8040-N. El recuadro muestra la zona de doblez. Las flechas dobles negras indican la dirección preferencial de la fábrica. A) Microfotografía del borde superior, las flechas blancas señalan la fábrica alineada de los filosilicatos de la matriz. B) Esquema mostrando los rasgos de la fábrica (Fr1, Fr2) y la dirección de compresión (Co) (véase texto).

partículas de color gris claro y fragmentos cristalinos en los barros oscuros, así como partículas calcáreas, semillas carbonizadas además de arena, cuarzo o bioclastos (concha marina), en forma de partículas gruesas en las pastas.

Tal como se ha planteado, las cerámicas Nimún y Baca muestran una textura granular con presencia de vidrio volcánico abundante y un reemplazo de las tobas por calcita tipo micrita. Desde el punto de vista geológico, al compararse los cuadros granulométricos de Nimun y Baca para los tamaños promedios de pómez, ambos grupos cerámicos llegan a ser arenas finas a medias. Las granulometrías promedio de vidrios de ambos llegan a ser arenas finas a limo grueso. Observando los porcentajes de pómez, cuarzo, tobas vitroclásticas tanto en Nimun como en Baca, ambos son muy similares. Entonces se puede decir que Nimun y Baca muestran una textura granular con tamaños de grano promedio que oscila entre arena fina a media; textura similar descrita en las tipologías cerámicas previas de la Vajilla Celestún Roja de Piña (1968), Ruz (1969) y Ball (1978). A diferencia de lo planteado por estos autores en las muestras analizadas no se hallaron bioclastos ni trazas de materia orgánica que pudiese evidenciar el uso de semillas carbonizadas.

Con respecto a la calcita, ésta es tipo micrita y puede englobar e invadir los fragmentos de roca y las tobas vitroclásticas reemplazando total o parcialmente sus componentes, hasta tal punto que borra la textura y mineralogía original, hecho ya señalado por Simmons \& Brem (1979). La calcita observada en los preparados es secundaria, producto de la lixiviación, y la porosidad primaria ha desaparecido todo o en parte debido al relleno secundario de carbonato en forma de películas de micrita o microesparita. Siendo un origen secundario, no es dable tomar las calcitas, como indicador para interpretar correlaciones cerámicas de sitios arqueológicos basados en este rasgo, ya que el mismo es totalmente aleatorio y de carácter secundario y no está ligado a la pasta cerámica original. Como se indicó en párrafos anteriores, Brainerd (1958, p.70) había indicado que la mezcla de arcilla y esquirlas de vidrio con calcita identificadas por Shepard (1964), en algunas cerámicas prehispánicas yucatecas, parecerían ser el resultado de un origen secundario.

Debido a la característica de la precipitación mineral secundaria, cementación y reemplazamiento total o parcial de componentes, tales rasgos deben ser tomados en cuenta al realizar análisis químicos elementales ya que los porcentajes de elementos móviles puede aumentar o disminuir significativamente debido a los procesos diagenéticos. Por tanto, la omisión de estos hechos llevaría a errores en cuanto a la interpretación y conclusión sobre los rasgos primarios de los elementos constituyentes de las cerámicas procedentes de la costa peninsular de Yucatán. 


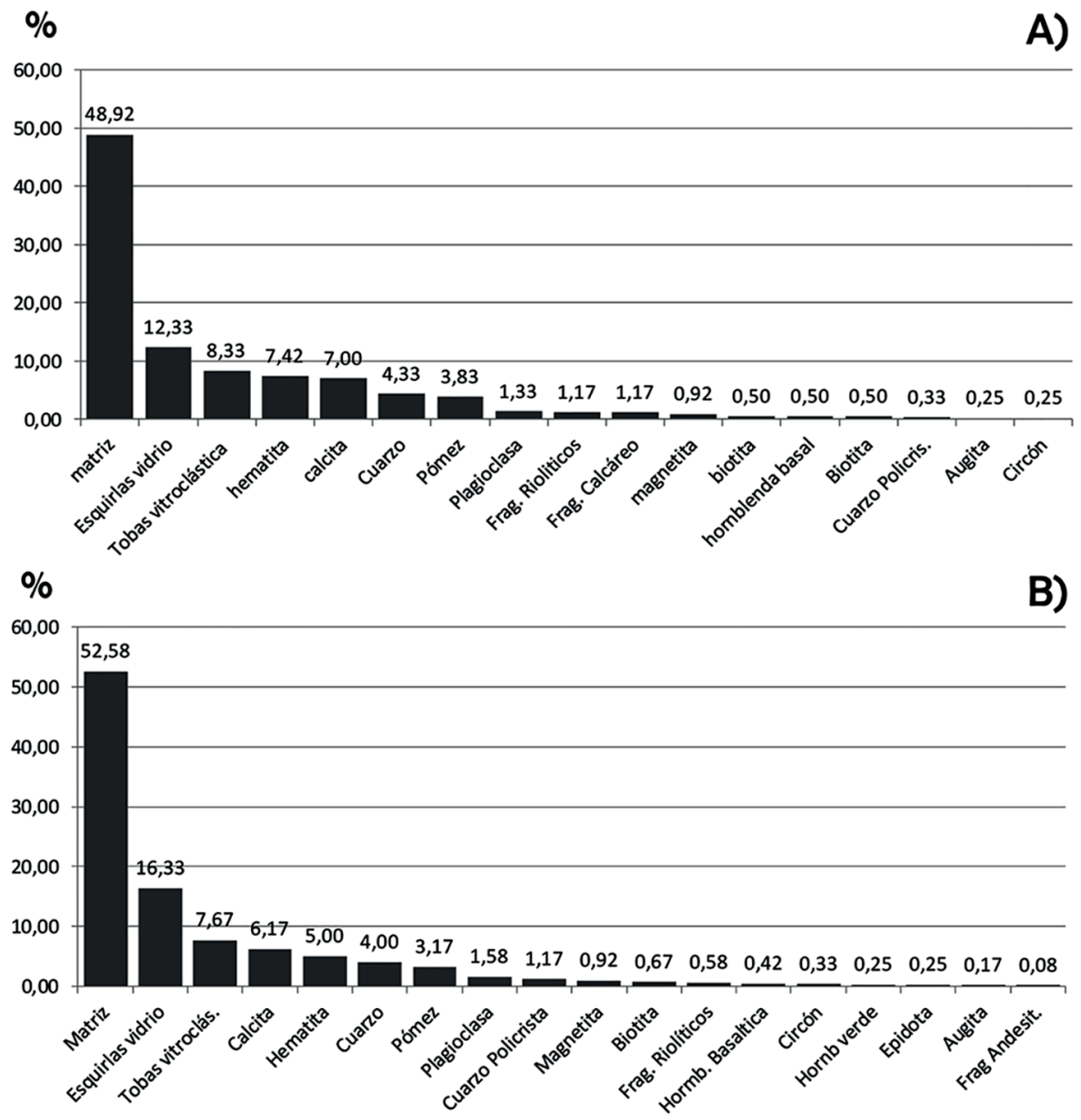

Fig. 9: Grafico A) Nimun matriz y componentes detríticos promedio. Gráfico B) Baca matriz y componentes detríticos promedio.

Como hipótesis de trabajo, se infiere que la procedencia de las tobas vitroclásticas y fragmentos riolíticos, se puede atribuir a rocas de origen volcánico de composición ácida, sean estas rocas riolitoides, fragmentarias ácidas como tobas o ignimbritas; lo cual son rocas no propias de la península de Yucatán como lo muestran las evidencias de campo y los mapas geológicos. Sin embargo, es recomendable realizar análisis químicos modales de estos fragmentos vitrios a fin de confirmar la hipótesis de trabajo.

Petrográficamente, Nimún y Baca, tienen pastas texturalmente similares, es decir usaron las mismas "recetas de pastas". Las diferencias entre estos grupos cerámicos de la Vajilla Celestún
Roja, están principalmente relacionadas con la estética del tratamiento de la superficie, formas de vasijas y funciones de uso particulares. Debido a estas razones, en la tipología propuesta de la costa peninsular de Yucatán, se han establecido dos grupos cerámicos, Nimún y Baca que fueron integrados en una misma Vajilla, es decir "Celestun Roja".

Hay que ser cautelosos con las interpretaciones aún con los resultados del análisis petrográfico, no se pueden descartar los supuestos previos que explican el origen de su manufactura. Las cerámicas Nimún y Baca bien se pudieron haber manufacturado en la costa con materias primas (arcillas y constituyentes) traídas desde otras áreas cercanas o distantes, o bien también pudieron haberse 

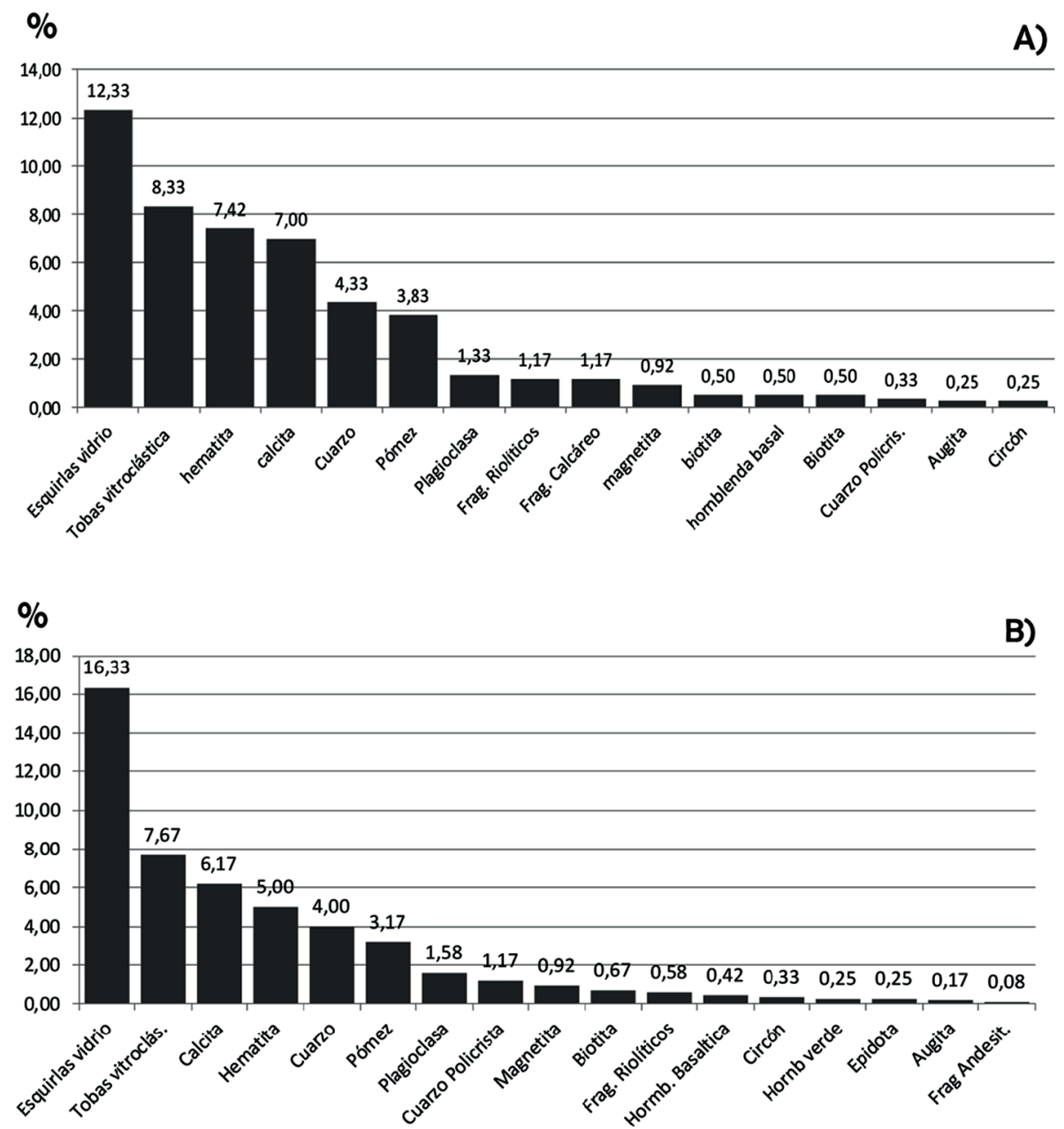

Figura 10 A y B: Grafico A) Nimun componentes detríticos promedio: Silicoclásticos y Carbonatados. Grafico B) Baca componentes detríticos promedio: Silicoclásticos y Carbonatados.

elaborado tierra adentro mezclando materiales locales y foráneos, con un control productivo por parte de los grupos humanos que intervenían en las redes costeras de intercambio de bienes del periodo Clásico Tardío peninsular. Entonces, es posible que la caracterización de los materiales siga apuntando hacia la costa de Campeche o hacia la región de los "Chenes". Cabe señalar, que las cerámicas del Puuc no muestran restos de cuarzo sino mas bien calcita y/o vidrio, en tanto que en la región de los "Chenes" si es más frecuente hallar cuarzos y/o vidrios volcánicos como minerales constituyentes de las cerámicas prehispánicas del periodo Clásico Tardío. Lo que si no deja lugar a dudas es su distribución amplia y abundante en sitios costeros y cercanos al litoral peninsular.

Las prácticas de manufactura artesanal especializada en Nimún y no especializada en Baca se pueden evidenciar en las láminas delgadas. De acuerdo al presente estudio, se destacan dos rasgos importantes relacionados con la manufactura de los bordes: a) fracturas por tensión y b) alineación de los filosilicatos.

Por otra parte, los rasgos petrográficos de fractura por tensión y alineación de filosilicatos han sido interpretados como rasgos que se formaron 
durante el proceso de modelado en los bordes. Las observaciones petrográficas en los resultados obtenidos sugieren un conocimiento especializado por parte de los alfareros responsables de la modelación de piezas y preparación de arcillas. Estos artesanos sabían cómo, de las mismas paredes de los cuellos de las vasijas, formar bordes exageradamente "acampanados", y también los cuellos anchos de las ollas Nimun. Al doblar los bordes se formaron las fracturas por tensión, debido a que la arcilla ya había perdido mucha de su humedad. Sin duda alguna, aquí el conocimiento práctico de la plasticidad adecuada de la arcilla y constituyentes "antideformantes" como el vidrio y los cuarzos son sumamente importantes, sobre todo para el formado de piezas que requieren dimensiones espaciosas tanto en el cuerpo como en el orificio de la boca. Este rasgo de tensión sugiere que el borde del fragmento de una olla Nimún (8005-N) no fue añadido con posterioridad a la elaboración de las paredes del mismo.

Como se mencionó en párrafos anteriores, las ollas Nimun se usaron de manera acostumbrada como receptáculos funerarios, o bien para almacenar alimentos líquidos o acuosos durante las labores cotidianas. En el caso de las cazuelas Nimun o Baca por sus dimensiones exageradas requerían bordes doblados, los cuales servían como agarraderas para alzar y sujetar a las piezas. Es importante señalar que a esta forma cerámica no se le encuentra asociada con contextos rituales ni funerarios, únicamente se le ha hallado en excavaciones asociadas con áreas domésticas. La técnica de doblar bordes no es difícil de encontrar en esta forma de vasija, debido a que tal manera de modelar los bordes fue de uso acostumbrado entre los artesanos prehispánicos del norte de la Península de Yucatán. Lo que sí es trascendente es que los bordes de las cazuelas de la Vajilla Celestún Roja fueron doblados de manera delicada y expresados en una forma particular, permitiendo diferenciarlas muy fácilmente entre las cazuelas de la costa noroccidente y otras cerámicas procedentes del interior de la península yucateca.

Por otra parte, la alineación de filosilicatos, evidencia prácticas alfareras en el formado de las piezas menos elaboradas como es el caso de la muestra cerámica $8040-\mathrm{N}$ el cual corresponde a un fragmento de cazuela. En las cerámicas de uso común es habitual que el alfarero en la etapa final del proceso de modelado, doble hacia el exterior el sobrante de arcilla de recipientes de gran tamaño sin poner mucha atención al acabado final del borde, lo que da como resultado que durante este proceso se forme el rasgo identificado en el análisis petrográfico.

Como se desprende del texto, la identificación de rasgos petrográficos como indicadores de prácticas alfareras del pasado, conlleva a un campo más amplio en el enfoque petrográfico que no solo incluye la caracterización textural y mineral de las pastas sino también la realización de interpretaciones de tipologías o bien para el intercambio de bienes por parte de los grupos humanos del pasado. El como se elaboraron los artefactos, son preguntas importantes en la caracterización petrográfica de los estudios de cerámica.

\section{AGRADECIMIENTOS}

Extendemos nuestro agradecimiento a las autoridades del Consejo Nacional de Arqueología del Instituto Nacional de Antropología e Historia de México por autorizar el análisis de las muestras cerámicas. Agradecimiento a las autoridades académicas y administrativas de nuestras respectivas instituciones académicas, la Universidad de Costa Rica (UCR, Proyecto No. 113-B2A26 UCR y la Licencia Sabática otorgada), Escuela Centroamericana de Geología (E.C.G) y la Universidad Autónoma de Yucatán (UADY, Sistema de Proyectos (SISTPROY) "Petrografía cerámica en el área Maya con clave FANT 20130007-FCA/UADY" y "Estudios Tecnológicos de las cerámicas depositadas en el Taller de Arqueología con clave FCA-UADY, FANT-20100003". Al Sr. Ronald L. Bishop (Smithsonian Institution) por sus valiosas observaciones y correcciones al documento, a Jeffrey Dobereiner por su gentileza en la traducción así como a Tony Flores Ramayo por la redacción estilística del texto. A nuestros colegas de la FCA-UADY en la persona de Rafael Cobos (director del Proyecto Arqueológico Uaymil) y del Instituto Nacional de Antropología e Historia (INAH-Yucatán) en 
la persona de Thelma Sierra Sosa (directora del proyecto Arqueológico Xcambó) y en la persona de Armando Inurreta (director del Proyecto Isla Piedras) del Museo Estatal de Arizona. A Heajoo Chung Seu (Proyecto de Petrografía, Láminas delgadas de Jaina, Colección Ceramoteca Centro INAH-Yucatán) de Busan University of Foreign Studies por brindarnos la oportunidad de estudiar desde el punto de vista geológico, las cerámicas arqueológicas de la costa peninsular. A los correctores anónimos del documento, nuestro agradecimiento.

\section{REFERENCIAS}

AHR, W. M., 2008: Geology Of Carbonate Reservoirs.- 277 págs. Ed. John Wiley \& Sons, New Jersey.

BALL, J., 1978: Archaeological pottery of the Yucatan-Campeche coast.- En: EATON, D. \& BALL, J. (eds): Studies in the archaeology of coastal Yucatan and Campeche, México.- Middle American Research Institute, Pub. Tulane University, New Orleans, 46: 69-146.

BATHURST, R. G., 1975: Carbonate sediments and their diagenesis.- 658 págs. Ed. Elsevier, Amsterdam.

BISHOP, R. L., BLACKMAN, M. J., FOLAN, W., FORSYTH, D. W. \& SEARS, E., 2006: Observaciones iniciales sobre el consumo de la cerámica de Champotón.- Los Investigadores de la Cultura Maya. 24( I): 137-145.

BRAINERD, G.,1958: The Archaeological Ceramics of Yucatan.- Anthropological Records, Vol. 19: 378 págs. Ed. University of California Press, Berkeley.
CORRALES, I., ROSELL, J., SÁNCHEZ, L., VERA, J. \& VILAS, L., 1977: Estratigrafía.- 718 págs. Ed. Rueda, Castellón, España.

DURAND, N., CURTIS, M., \& MATTHEW, C., 2010: Calcium Carbonate Features.En: STOOPS, G., MARCELINO, V. \& MEES, F. (eds): Interpretation of Micromorphological Features of Soils and Regoliths.- Elsevier, 149-194.

FOLK, R., 1974: Petrology of Sedimentary Rocks.- 190 págs. Ed. Hemphill Publishing, Austin, Texas.

FORD, A. \& GLICKEN, H., 1987: The significance of Volcanic Ash Tempering in the ceramics of the central Maya Lowlands.En: RICE, P.M. \& SHARER, R.J. (eds): Maya Ceramics Papers from the 1985 Maya Ceramic Conference.- British Archaeological Reports (BAR), 345: 490-502.

FORD, A. \& ROSE, W., 1995: Volcanic Ash in Ancient Maya Ceramics of the Limestone Lowlands: Implications for Prehistoric Volcanic Activity in the Guatemala Highlands.- Journal of Volcanology and Geothermal Research 66: 149-162.

FORD, A. \& SPERA, F., 2007: Fresh Volcanic Glass Shards In The Pottery Sherds of the Maya Lowlands.- Research Reports in Belizean Archaeology 4: 111-118.

GREGOR, M., KOVÁC, M., KOVÁR, B. \& ALVARADO, S., 2013: Nuevos hallazgos de mineralogía y petrografía de la cerámica 
de Uaxactún.- En: ARROYO, B. \& MÉNDEZ, L., (eds): XXVI Simposio de Investigaciones Arqueológicas en Guatemala. Ciudad de Guatemala, Guatemala, 183-193.

JIMÉNEZ, S., 2009: La esfera cerámica Canbalam.- En: BOSCH G. \& ANNICK D., (eds): Cronología y periodización en Mesoamérica y el norte de México.- V Coloquio. Universidad Nacional Autónoma de México \& Instituto de Investigaciones Antropológicas. México, 365-388.

JIMÉNEZ, S., CEBALLOS, T. \& SIERRA, T. , 2006a: Las Insólitas Cerámicas del Litoral Noroeste de la Península de Yucatán, en el Clásico Tardío. La Esfera Cerámica Canbalam.- En: MERINO, B., L. \& GARCÍA, A. (eds): La Producción Alfarera del México Antiguo. Instituto Nacional de Antropología e Historia. Colección Científica, México, D.F. III:345-371.

JIMÉNEZ, S., BELMAR, R., SIERRA, T. \& CHUNG, H., 2006b: Un estudio tecnológico de la Cerámica de Pasta Fina "Chablekal temprano e Isla Fina" del sitio costero de Xcambó, Yucatán.- Los Investigadores de la Cultura Maya. Universidad Autónoma de Campeche, 14 (2):501-506.

JIMÉMEZ, S., 2002: La cronología cerámica del puerto Maya de Xcambó, Costa Norte de Yucatán: Complejo Cerámico Xcambó y Complejo Cerámico Cayalac.- Tomo I: 311 págs. Universidad Autónoma de Yucatán, Mérida, Yucatán, México [Tesis Lic].

JONES, L. D.,1986: Lowland Maya Pottery: The Place of Petrographic Analysis.- British Archaeol. Reports (BAR), 288:113.
LE MAITRE, R.,1989: A Classification of Igneous Rocks and Glossary of Terms.193 págs. Ed. Blackwell, Oxford.

MANIATIS, Y., 2009: The Emergence of Ceramic Technology And Its Evolution as Revealed with the use of Scientific Techniques.- En: SHORTLAND A. J., FREESTONE I., C. \& REHREN, T., (eds): From Mine to Microscope. Advances in the Study of Ancient Technology.- Oxbow Books, Oxford: 11-28.

MOORE, C. H., 1997: Carbonate Diagenesis and Porosity [2a ed.].- 317 págs. Ed. Elsevier, Amsterdam.

NICHOLS, G., 2009: Sedimentology and Stratigraphy [2a ed.].- 431 págs. Ed. Wiley Blackwell, New Jersey.

OBANDO, L. G., JIMÉNEZ, S., \& KUSSMAUL, S., 2011: Estudio petrográfico de cerámicas Mayas, clásico tardío (600-900 dc.) Chinikihá, Chiapas, México.- Rev.Geol. Amér. Central, 44: 103-120.

PETERSON, S., 2009: Thin-Section Petrography ofCeramic Material.-Instap Archaeological Excavation Manual 2.- 19 págs. Ed. Instad Academic Press, Philadelphia.

PIÑA, R.,1968: Jaina la casa en el agua.- 137 págs. Ed. Instituto Nacional de Antropología e Historia. México, D.F.

RANDS, R. \& BARGIELSKI, M., 1992: Integrative approaches in the Compositional Characterization of Ceramic Pastes.- En: NEFF, H. (ed.): Chemical characterization 
of Ceramic Pastes in Archaeology, Monographs in World Archaeology.Prehistory Press, Madison: 7:31-57.

RAPP, G., 2009: Archaeo-mineralogy. Natural Science in Archaeology [2a ed.].- 366 págs. Ed. Springer-Verlag Berlin.

RIEDERER, J., 2004: Thin section Microscopy Applied to the Study of Archaeological Ceramics.Hyperfine Interactions, 154: 143-158.

RUZ, A., 1969: La Costa de Campeche en los Tiempos Prehispánicos.- 316 págs. Prospección cerámica y Bosquejo Histórico XVIII. Ed. Instituto Nacional de Antropología e Historia, México, D.F.

RYE, O., 1981: Pottery Technology, Principles and Reconstructions.- 150 págs. Manual in Archaeology, Smithsonian Institution, Washington D.C.

\section{SERVICIO GEOLÓGICO MEXICANO} (SGM), 2007: Carta Geológica-Minera. Estados de Campeche Quintana Roo y Yucatán.- Escala 1:500.000, Servicio Geológico Mexicano, México.

SHEPARD, A., 1939: Technological notes on the pottery of San Jose.- En THOMPSON, E.S. (ed.): Excavations at San Jose, British Honduras.- Carnegie Institution of Washington, 506: 251-277.

SHEPARD, A., 1964: Ceramic Development of the Lowland and Higland Maya.- $35^{\text {th }}$ International Congress of Americanists, México, D.F., 1: 249-262.

SIMMONS, M. \& BREM, G., 1979: Analysis and Distribution of Volcanic Ash. Tempered Pottery in the Lowland Maya Area.American Antiquity, 44(1): 79-91.
SMITH, R., 1971: The pottery of Mayapan: including studies of ceramic material from Uxmal, Kabah and Chichén Itza [2 vols.].- 456 págs. Harvard University, Cambridge.

STOLTMAN, J., 2001: The role of Petrography in the study of Archaeological ceramics.En: GOLDBERG ,P., HOLLIDAY ,V. \& FERRING, R., (eds): Earth Sciences and Archaeology.- Springer, New York: 297-326.

SUNAHARA, K., 2009: Ancient Maya ceramic economy in the Belize River Valley Region. Petrographic analyses.- British Archaeological Reports (BAR), 2018: 88.

VERA， J., 1994: Estratigrafía, Principios y Métodos.- 806 págs. Ed. Rueda. Castellón.

VARELA, C. \& LECLAIRE, A.,1999: Enigmas cerámicos: análisis petrográfico de la cerámica pizarra de Oxkintok, Yucatán, México.- Rev. Española de Antropología Americana, 29:101-129.

WALTHER, J., 2009: Essentials of Geochemistry [2 $2^{\mathrm{a}}$ ed.].- 767 págs. Ed. Jones and Bartlett Publishers, Southern Methodist University, Massachusetts.

WENTWORTH, C. K., 1922: A Scale Of Grade and Class Terms for Clastic Sediments.Journal Geology, 30: 377-392.

WILLIAMS-BECK, L. A.,1999: Tiempo en trazos: Cerámica de la región de los Chenes, Campeche, México.- 309 págs. Ed. Gobierno del Estado de Campeche. Instituto de Cultura de Campeche, Universidad Autónoma de Campeche, Campeche, México. 